LOCKHEED MARTINT/7

ENVIRONMENTAL

RESTORATION

PROGRAM

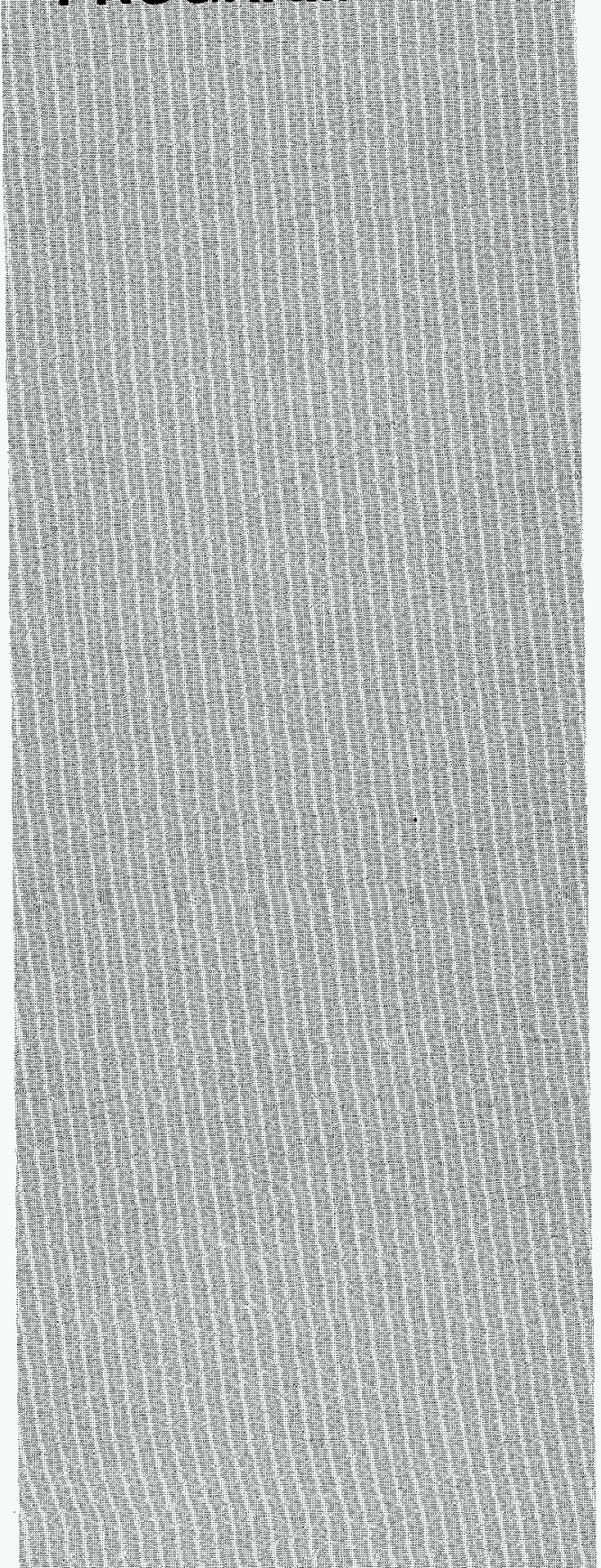

Y/ER-290

\section{Sampling and Analysis Plan for Phase II of the Bear Creek Valley Treatability Study Oak Ridge Y-12 Plant, Oak Ridge, Tennessee}

\section{RECEIVED}

JUL 021997

OSTI

This document has been approved by the Y-12 Plant Technical Information pffice for release to the public. Date: $5 / 13 / 97$

ENERGY SYSTEMS

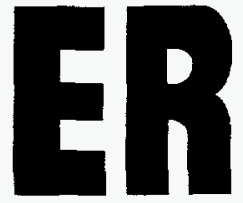




\section{Science Applications International Corporation}

contributed to the preparation of this document and should not be considered an eligible contractor for its review. 


\title{
Sampling and Analysis Plan for Phase II of the Bear Creek Valley Treatability Study Oak Ridge Y-12 Plant, Oak Ridge, Tennessee
}

Date Issued-May 1997

\author{
Prepared by \\ Science Applications International Corporation \\ Oak Ridge, Tennessee \\ under subcontract 78B-99069C \\ Prepared for the \\ U.S. Department of Energy \\ Office of Environmental Management \\ under budget and reporting code EW 20 \\ Environmental Management Activities at the \\ OAK RIDGE Y-12 PLANT \\ Oak Ridge, Tennessee 37831 \\ managed by \\ LOCKHEED MARTIN ENERGY SYSTEMS, INC. \\ for the \\ U.S. DEPARTMENT OF ENERGY \\ under contract DE-AC05-84OR21400
}




\section{DISCLAMMER}

Portions of this document may be illegible in electronic image products. Images are produced from the best available original document. 


\section{PREFACE}

The Bear Creek Valley Treatability Study Sampling and Analysis Plan was prepared under the Environmental Restoration Program to support the investigation of the practicality of the use of passive, in situ treatment systems to remove contaminants from the Bear Creek Valley Characterization area. This work was performed under Work Breakdown Structure (WBS) 1.1.0241.10.34.20. This report will be used to direct investigations during Phase 2. 


\section{CONTENTS}

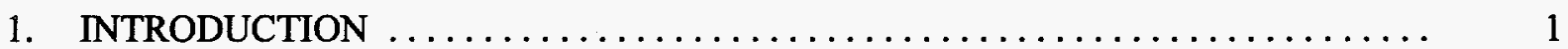

2. MEDIA PERFORMANCE EVALUATION $\ldots \ldots \ldots \ldots \ldots \ldots \ldots \ldots \ldots \ldots \ldots \ldots$

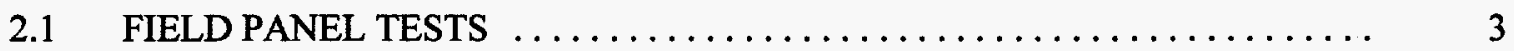

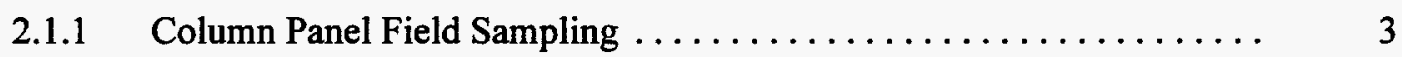

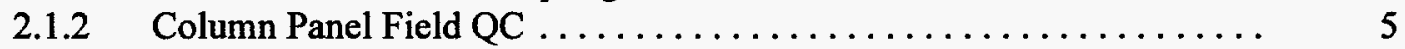

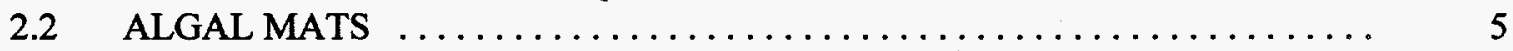

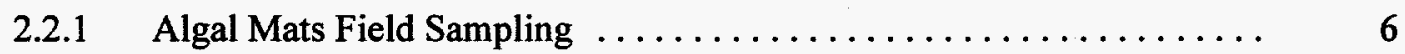

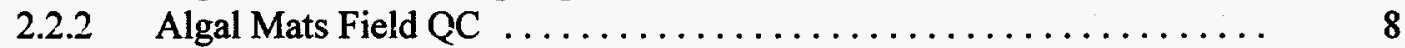

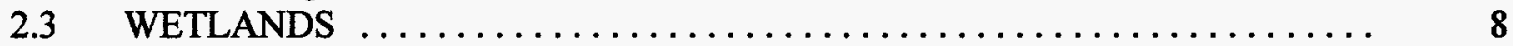

2.3.1 Wetlands Field Sampling $\ldots \ldots \ldots \ldots \ldots \ldots \ldots \ldots \ldots \ldots \ldots \ldots \ldots \ldots \ldots$

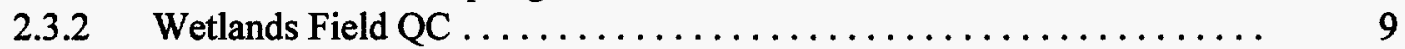

3. QUALITY ASSURANCE PROJECT PLAN $\ldots \ldots \ldots \ldots \ldots \ldots \ldots \ldots \ldots \ldots \ldots \ldots$

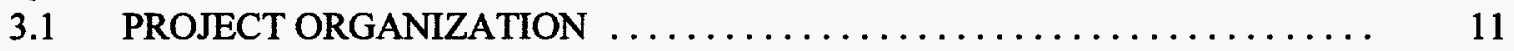

3.1.1 Project Personnel Responsibilities ..................... 11

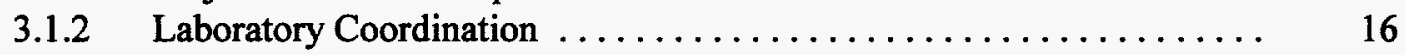

3.2 QA OBJECTIVES FOR DATA MEASUREMENT $\ldots \ldots \ldots \ldots \ldots \ldots \ldots \ldots \ldots \ldots$

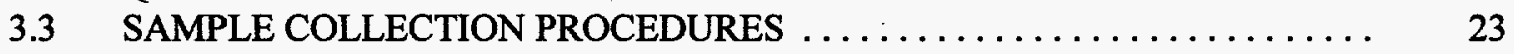

3.3.1 Groundwater and Surface Water Sampling ............... 23

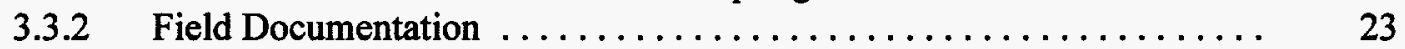

3.3.3 Sample Containers and Holding Times $\ldots \ldots \ldots \ldots \ldots \ldots \ldots . \ldots \ldots$

3.3.4 Sample Packaging and Preservation $\ldots \ldots \ldots \ldots \ldots \ldots \ldots \ldots \ldots . \ldots \ldots \ldots$

3.3.5 Decontamination of Equipment and Devices ............... 27

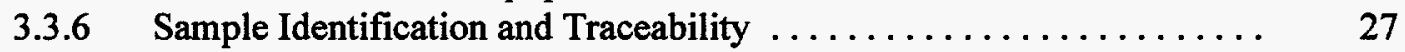

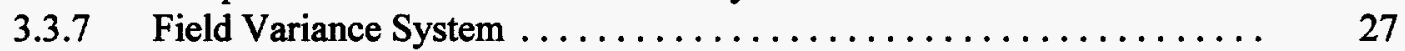

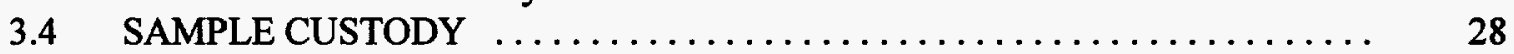

3.5 CALIBRATION PROCEDURES AND FREQUENCY $\ldots \ldots \ldots \ldots \ldots \ldots \ldots . \ldots \ldots$

3.5.1 Field Instrument Calibration Procedures and Frequency . . . . . . . 28

3.5.2 Laboratory Instrument Calibration Procedures and Frequency . . . . . . 30

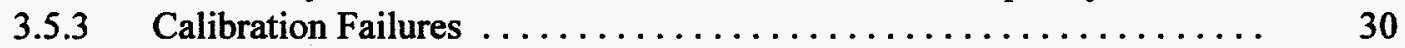

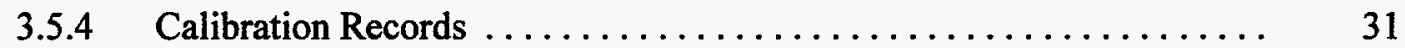

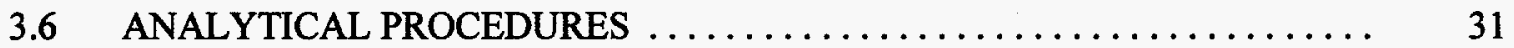

3.6.1 Field Analytical Methods . . . . . . . . . . . . . . . . . . . . 31

3.6.2 Laboratory Analytical Methods .................... 31

3.7 DATA REDUCTION, VERIFICATION/VALIDATION, AND REPORTING .. 32

3.7.1 Field Data Reduction and Evaluation ..................... 33

3.7.2 Analytical Laboratory Data Reduction and Evaluation .......... 33

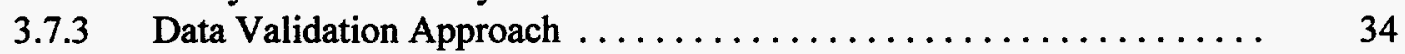

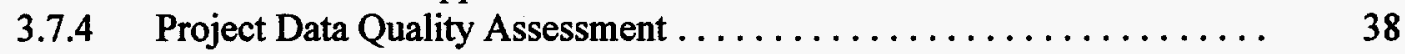

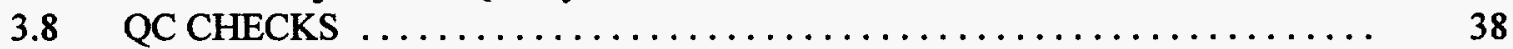

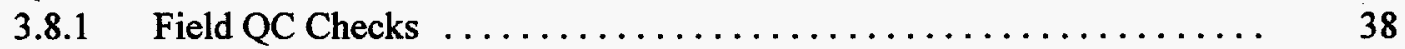

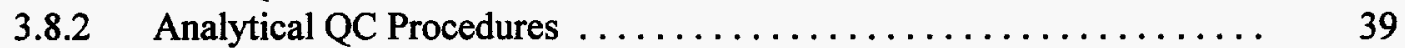

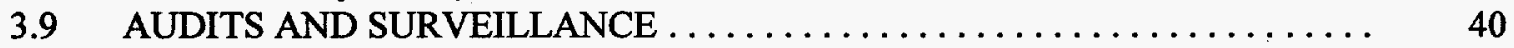

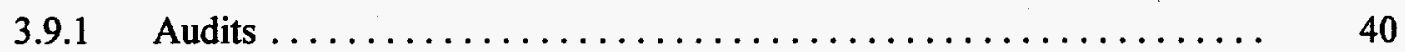


3.9.2 Surveillance $\ldots \ldots \ldots \ldots \ldots \ldots \ldots \ldots \ldots \ldots \ldots \ldots \ldots \ldots \ldots \ldots$

3.10 PREVENTIVE MAINTENANCE PROCEDURES/SCHEDULES $\ldots . . \ldots \ldots .41$

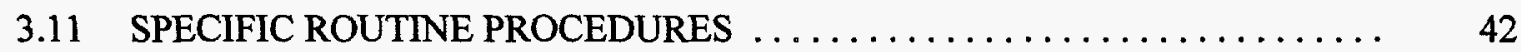

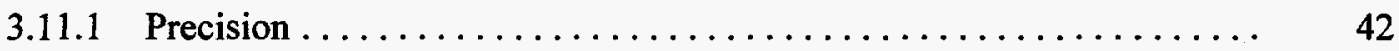

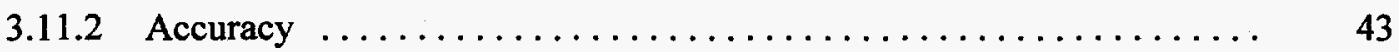

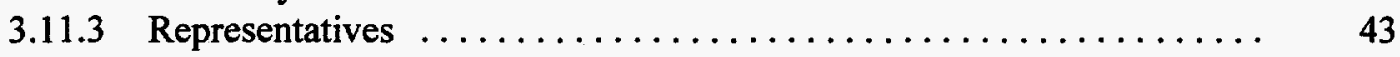

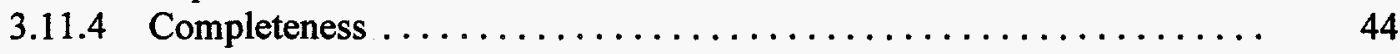

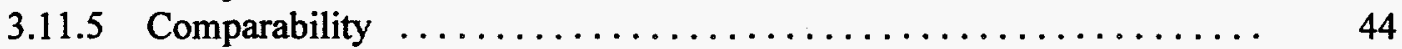

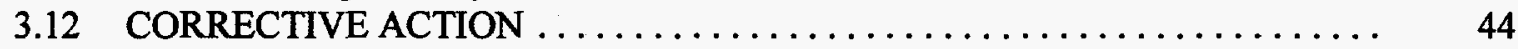

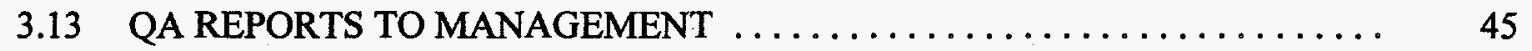

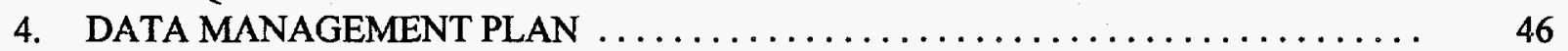

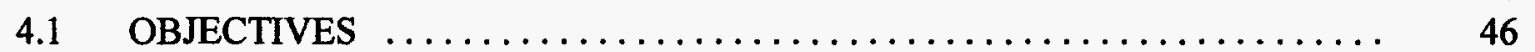

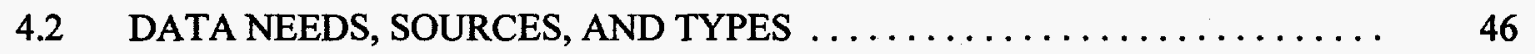

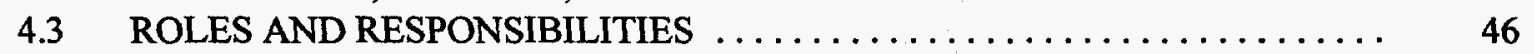

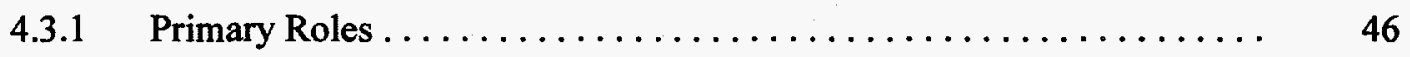

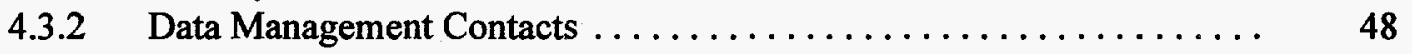

4.4 DATA MANAGEMENT ACTIVITIES $\ldots \ldots \ldots \ldots \ldots \ldots \ldots \ldots \ldots \ldots \ldots . \ldots \ldots \ldots \ldots$

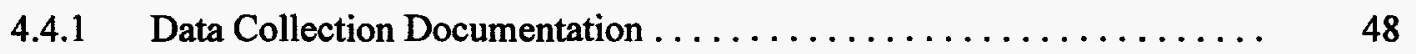

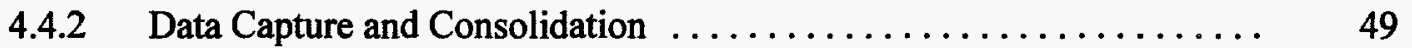

4.4.3 Data Verification and Validation ..................... 50

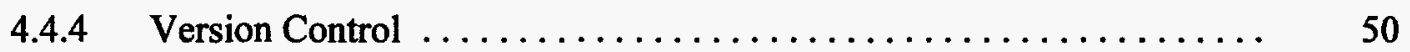

4.5 TRANSMITTALS AND ARCHIVAL OF DATA $\ldots \ldots \ldots \ldots \ldots \ldots \ldots \ldots$

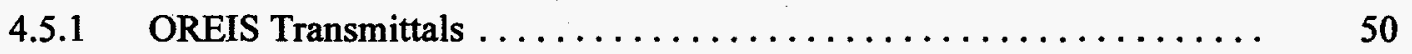

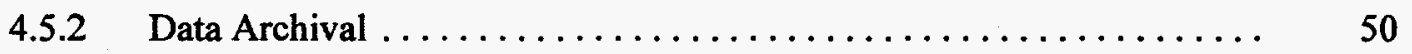




\section{FIGURES}

1. General site layout $\ldots \ldots \ldots \ldots \ldots \ldots \ldots \ldots \ldots \ldots \ldots \ldots \ldots \ldots \ldots \ldots \ldots \ldots \ldots \ldots \ldots \ldots, 2$

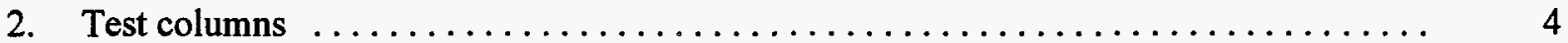

3. New algal bioreactor figure from MATS $\ldots \ldots \ldots \ldots \ldots \ldots \ldots \ldots \ldots \ldots \ldots, 7$

4. Configuration of the wetlands and sampling locations $\ldots \ldots \ldots \ldots \ldots \ldots \ldots, 10$

5. Organizational chart $\ldots \ldots \ldots \ldots \ldots \ldots \ldots \ldots \ldots \ldots \ldots \ldots \ldots \ldots \ldots, 13$

6. Chain-of-custody record example $\ldots \ldots \ldots \ldots \ldots \ldots \ldots \ldots \ldots \ldots \ldots \ldots, 25$

\section{TABLES}

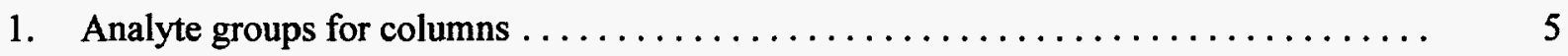

2. Analyte groups and number of samples for columns $\ldots \ldots \ldots \ldots \ldots \ldots \ldots \ldots$

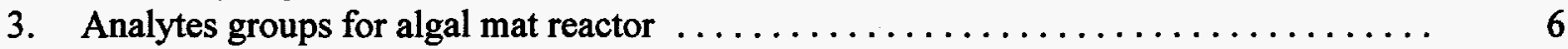

4. Analyte groups and number of samples for algal mat reactor $\ldots \ldots \ldots \ldots \ldots \ldots \ldots . \quad 8$

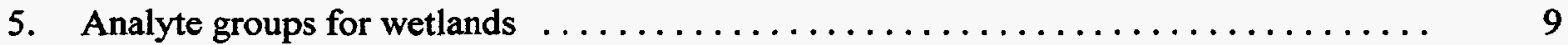

6. Analyte groups and number of samples for wetlands $\ldots \ldots \ldots \ldots \ldots \ldots \ldots \ldots \ldots$

7. Cross reference of EPA QAMS 005/80 and ES/ER/TM-4/R4 elements with the

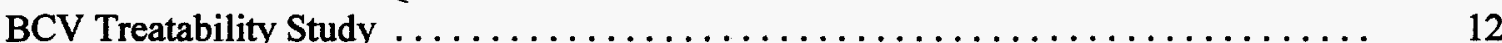

8. Key project personnel and affiliations $\ldots \ldots \ldots \ldots \ldots \ldots \ldots \ldots \ldots \ldots \ldots \ldots \ldots \ldots \ldots$

9. Surface water/groundwater DQO summary for BCV Treatability Study, Oak Ridge, Tennessee .......................................... 18

10. Analytical methods, parameters, and project quantitation limits for BCV Treatability Study Investigations, Oak Ridge, Tennessee $\ldots \ldots \ldots \ldots \ldots \ldots \ldots$

11. BCV Treatability Study sampling and support procedures $\ldots \ldots \ldots \ldots \ldots \ldots \ldots \ldots 24$

12. Container recommended for BCV Treatability Study Investigations,

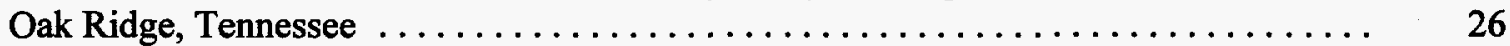

13. Field instrument uses, detection limits, and calibration $\ldots \ldots \ldots \ldots \ldots \ldots \ldots \ldots$

14. Summary of analytical hard-copy data deliverables $\ldots \ldots \ldots \ldots \ldots \ldots \ldots \ldots \ldots$

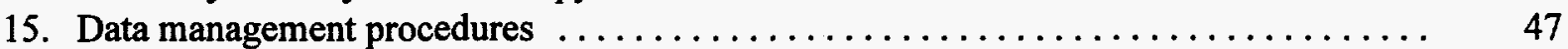




\section{ABBREVIATIONS}

ASTM

BCV

CLP

DMP

DOE

DQOs

EDD

EMEF

EPA

FCO

FOM

FSP

H\&S

ICP

LCS

M\&TE

MS/MSD

NCR

NIST

OR SMO

OREIS

ORNL

PARCC

QA

QAPjP

QAPP

QC

RPD

SAP

SRM

TDEC
American Testing and Materials

Bear Creek Valley

Contract laboratory Program

Data Management Plan

U.S. Department of Energy

Data Quality Objectives

electronic data deliverables

Environmental Management and Enrichment Facilities

U.S. Environmental Protection Agency

field change order

Field Operations Manager

Field Sampling Plan

Health \& Safety

inductively coupled plasma

laboratory control standards

materials and testing

matrix spike/matrix spike duplicate

Nonconformance Report

National Institute of Standards and Technology

Oak Ridge Sample Management Office

Oak Ridge Environmental Information System

Oak Ridge National Laboratory

precision, accuracy, representativeness, completeness, and comparability

quality assurance

Quality Assurance Project Plan

Quality Assurance Administration Procedure

quality control

relative percent difference

Sampling and Analysis Plan

standard reference material

Tennessee Department of Environment and Conservation 


\section{INTRODUCTION}

The Bear Creek Valley (BCV) Treatability Study is intended to provide site-specific data defining potential treatment technologies applicable to contaminated groundwater and surface water. This project directly supports Alternative 5 of the base action in the BCV Feasibility Study, and indirectly supports other alternatives through proof of concept. In that role, the ultimate goal is to install a treatment system that will remove uranium and nitrate from groundwater before it reaches Bear Creek. A secondary goal is the concurrent removal of technetium and several metals that impact ecological risk. This project is intended to produce hydraulic and treatment performance data required to design the treatment system to reach those goals. This project will also generate information that can be applied at other facilities within the Oak Ridge Reservation.

This report is the sampling and analysis plan (SAP) for the field work component of Phase II of the BCV Treatability Study. Field work for this phase of the BCV Treatability Study consists of media testing. In-field continuous flow tests will be conducted over an extended time period (5 weeks) to generate data on long-term treatment effects on potential treatment media including sorbents and zero valent iron, over 28 weeks for constructed wetlands treatment, and over 24 weeks for algal mats treatment. The SAP addresses environmental sampling at the S-3 Site at the Oak Ridge Y-12 Plant. Samples will be taken from groundwater, effluent from test columns, effluent from an algal mat reactor, and effluent from a pilot-scale wetland. This plan will be implemented as part of the BCV Phase II Treatability Study Best Management Practices Plan and in conjunction with the BCV Phase II Treatability Study Health and Safety Plan and the BCV Phase II Treatability Study Waste Management Plan.

Chapter 1 is a brief introduction to the BCV Phase II Treatability Study SAP. Chapter 2 contains the detailed lists of environmental sample locations, frequencies, analytes, and procedures for the media testing component of the BCV Phase II Treatability Study SAP. Figure 1 shows the general site layout for the area of field investigation for the BCV Phase II Treatability Study. Not included on this figure are the wetlands that are located at SS-4 in BCV.

Chapter 3 of the SAP is the Quality Assurance Project Plan (QAPjP) and includes lists of the sampling and analytical methodologies that will be followed by the BCV Phase II Treatability Study. Chapter 4 is the Data Management Plan (DMP). A site-specific mobilization checklist is contained in Appendix A. This checklist provides details of the field operations such as permit requirements, plant contacts and telephone numbers, and access requirements. 


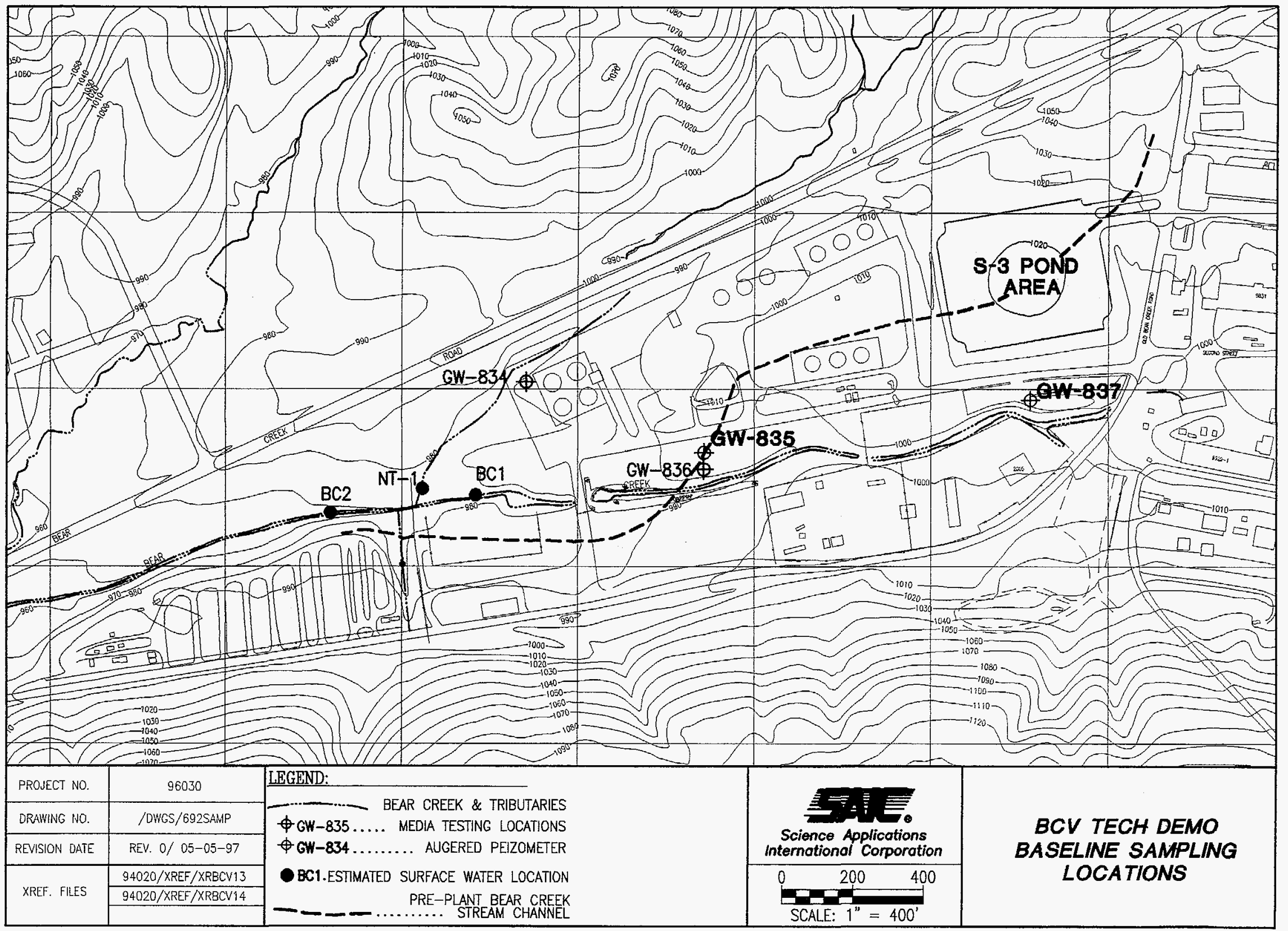

Fig. 1. General site layout. 


\section{MEDIA PERFORMANCE EVALUATION}

\subsection{FIELD PANEL TESTS}

The objective of in-field panel tests is to document the performance and effects of long-term continuous flow on each treatment medium in field column tests. In addition, the tests are intended to determine the impact of the treated water on native soil. A series of four test periods will be completed using mobile panel systems with up to six columns. The panel will be installed adjacent to temporary GW-837and GW-835. These will be pumped to provide test water on a continuous basis. The first test period will include four different treatment media, each one packed into a single column as depicted in Fig. 2. The effluent from the zero valent iron test columns will be directed to additional columns containing either peat or native soil. These additional treatments will test the compatibility of treated water with the surrounding subsurface environment.

Column performance will be measured based on the overall reduction in contaminant concentrations combined with the impact of other operational considerations such as clogging or release of hazardous components. Field data ( $\mathrm{pH}$, oxidation-reduction potential, conductivity, temperature, pressure, flow) will be collected every 2 days, and water samples will be collected and archived for laboratory analysis every three days, or as recommended based on technical direction gained by direct observations.

Each test will operate until breakthrough is evident or until 5 weeks have passed. At the termination point, test columns will be removed and replaced with a second set of columns. The materials packed into the second, third, and fourth series of columns will be dependent on the results of the previous test. The sampling frequency for each subsequent test after the first test may vary based on the results of the first test, however, for planning purposes it is assumed that the frequency of sampling will be the same for all tests. Each test will operate no longer than 5 weeks and will contain no more than six columns.

\subsubsection{Column Panel Field Sampling}

Figure 2 shows the configuration of the columns for test period 1 (TP1). Table 1 lists the analyte groups for each test, and Table 2 lists the number of samples anticipated for each analyte group. Lists of individual analytes within each analyte group are contained in the QAPjP (Chap. 3 of this document) and include information on analytical method, detection limits, container sizes, preservatives, and analytical data quality objectives (DQOs). Specifically this information is given in the following tables:

Table 9 Surface water/groundwater DQO summary for the BCV Treatability Study, Oak Ridge, Tennessee

Table 10 Analytical methods, parameters, and project quantitation limits for BCV Treatability Study, Oak Ridge, Tennessee

Table 12 Container requirements for BCV Treatability Study, Oak Ridge, Tennessee 

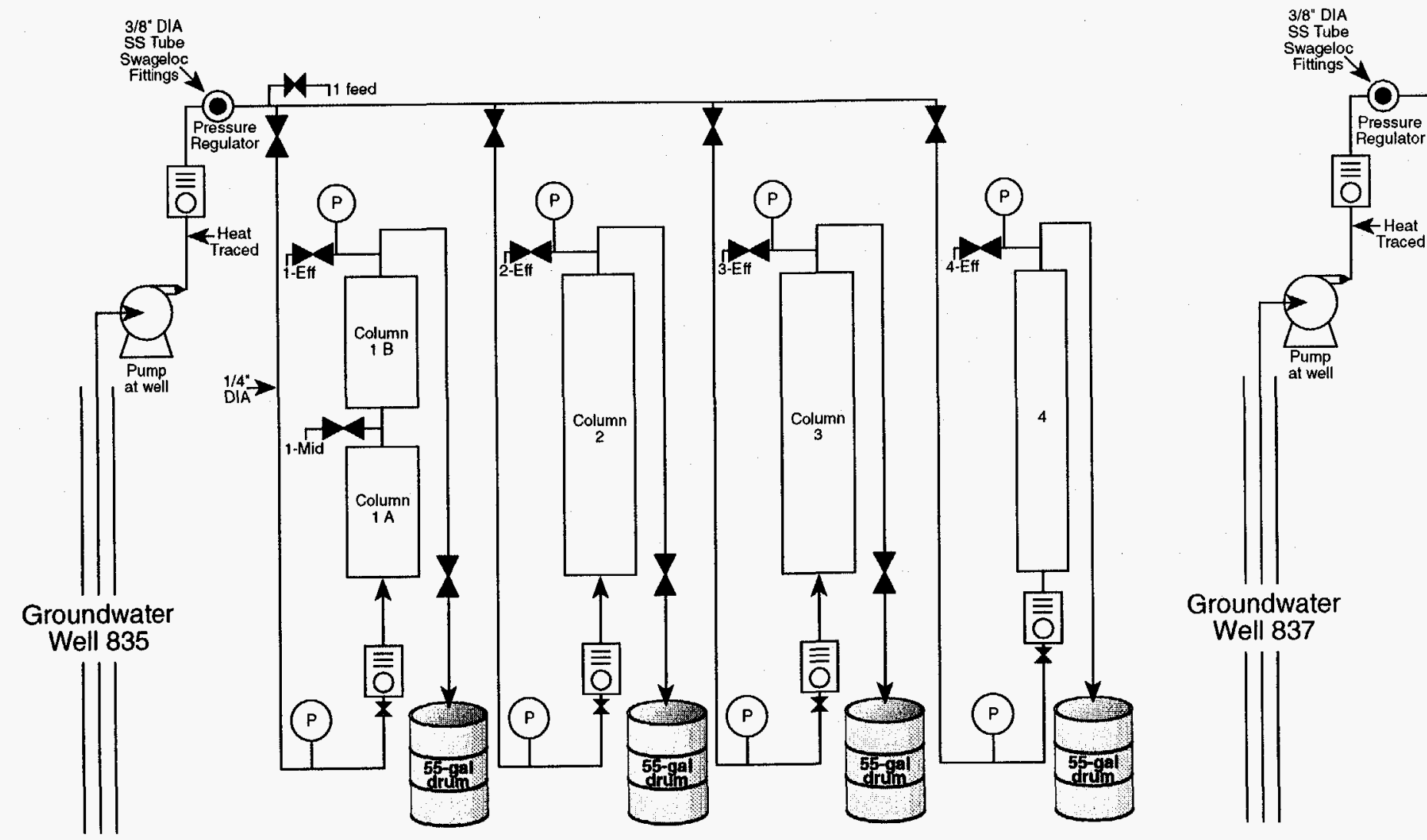

55-gal drums to totalize flow will be pumped once every 1-3 days and discharged to the ground.

- Columns $1 \mathrm{~A}$ and $1 \mathrm{~B}$ are each $1.25^{\prime} \times 1.5^{\prime \prime}$ DIA.

- Columns 2-3 are 2.5' x 3" DIA.

1 Flow valve $\quad$ Flow meter $\quad$ (P) Manometer

- Columns 4-6 are 2.5' x 3" DIA.

1-Feed - sample port for common feed to all columns at one location 1 - Mid - sample port for midpoint of column 1

1-Mid - sample port for midpoint of column 1 
Table 1. Analyte groups for columns

\begin{tabular}{cc}
\hline Analyte & Method \\
\hline Conductivity & EPA 120.1 \\
pH & EPA 150.1 \\
Temperature & EPA 170.1 \\
Eh & Electrometric \\
Dissolved oxygen & EPA 360.1 \\
Turbidity & Turbidiometer \\
Uranium & ICP \\
Nitrate/Nitrite & HACH kit and EPA 353.1 \\
Metals & ICP \\
Alkalinity & EPA 310.1 \\
TSS/TOS & EPA 160.1/160.2 \\
Tc-99 & Liquid scintillation \\
\hline
\end{tabular}

Lists of sampling procedures for surface water and groundwater are contained in the QAPjP (Sect. 3.3) and include information on field instrument uses and detection limits. Specifically, the information is given in the following tables:

Table 11 Sampling and support procedures for BCV Treatability Study, Oak Ridge, Tennessee

Table 13 Field instrument uses, detection limits, and calibration for BCV Treatability Study, Oak Ridge, Tennessee

\subsubsection{Column Panel Field QC}

Quality control (QC) samples will be collected at a frequency identified in the QAPjP to assess the quality of sampling. Field QC samples include blanks, rinsates, and duplicates. Equipment rinsates will be collected at a rate of approximately $5 \%$ of the samples collected, and field duplicates will be collected at a frequency of $10 \%$ of the samples collected. The number of QC samples for the column testing is listed in Table 2.

\subsection{ALGAL MATS}

The objective of algal mat testing is to determine the long-term capacity of mats to remove metals and nitrate from groundwater.

In parallel to the column panel tests, an algal mat reactor will be plumbed to receive a continuous flow of groundwater from the same well used to feed the columns. The mats will be monitored twice weekly for influent and effluent water quality criteria ( $\mathrm{pH}$, Eh, conductivity, temperature, nitrate). Effluent samples will be collected once per week for metals and nitrate analyses. The mats will be maintained for 24 weeks to establish a long-term uptake rate. At the completion of the treatment period, solids samples will be collected from three locations within the reactor to determine uptake relative to biomass. 
Table 2. Analyte groups and number of samples for columns

\begin{tabular}{|c|c|c|c|c|c|c|c|c|}
\hline Analyte & $\begin{array}{l}\text { Number } \\
\text { of feed } \\
\text { samples } \\
\text { per } \\
\text { column }\end{array}$ & $\begin{array}{l}\text { Number of } \\
\text { effluent } \\
\text { samples } \\
\text { per } \\
\text { column }\end{array}$ & $\begin{array}{c}\text { Total } \\
\text { samples } \\
\text { per } \\
\text { column }\end{array}$ & $\begin{array}{c}\text { Duplicates } \\
\text { @ } 10 \%\end{array}$ & $\begin{array}{c}\text { Rinsates } \\
\text { (a) } 5 \%\end{array}$ & $\begin{array}{l}\text { Total per } \\
\text { column }\end{array}$ & $\begin{array}{c}\text { Total per } \\
\text { series }^{a}\end{array}$ & $\begin{array}{c}\text { Total for } 4 \\
\text { series }\end{array}$ \\
\hline $\begin{array}{l}\text { Field } \\
\text { process }^{b}\end{array}$ & 13 & 18 & 31 & & & 31 & 186 & 744 \\
\hline Nitrate $^{c}$ & 1 & 4 & 5 & 1 & 1 & 7 & 42 & 168 \\
\hline $\mathrm{U} / \mathrm{metals}^{d}$ & 4 & 12 & 16 & 2 & 1 & 19 & 114 & 456 \\
\hline Tc- $99^{e}$ & 1 & 4 & 5 & 1 & 1 & 7 & 42 & 168 \\
\hline TSS/TOS & 2.5 & 6 & 8.5 & 1 & 0.5 & 10 & 60 & 240 \\
\hline
\end{tabular}

Each series will have no more than 6 columns and run no longer than 5 weeks.

b Field process measurements will be made every 2 days on the feed and effluent.

c Nitrate will break through the columns within first week if not sooner.

d Columns 1-4 have the same feed at Well 835. Columns 5-6 have the same feed at Well 837. Number of feed samples analyzed per test prorated by sampling on average every 3 days at Wells 835 and 837 . This gives 35 days $/ 3$ days average per sample $\times 2$ sites $=12$ per site $\times 2$ $=26$ total feed samples $/ 6$ columns or 4 per column per series.

e Tc-99 is very low in both wells. Assume that samples will not be analyzed extensively for Tc-99.

$f$ Assume to be one half of the number of U/metals samples.

\subsubsection{Algal Mats Field Sampling}

Figure 3 shows the configuration of the algal mat and includes sampling locations. Table 3 lists the analyte groups, and Table 4 lists the number of samples anticipated for each analyte group. Lists of individual analytes within each analyte group are contained in the QAPJP (Chap. 3 of this document) and include information on analytical method, detection limits, container sizes, preservatives, and analytical DQOs (Tables 9, 10, and 12).

Table 3. Analyte groups for algal mat reactor

\begin{tabular}{cc}
\hline Analyte & Method \\
\hline Conductivity & EPA 120.1 \\
$\mathrm{pH}$ & EPA 150.1 \\
Temperature & EPA 170.1 \\
Eh & Electrometric \\
Dissolved oxygen & EPA 360.1 \\
Turbidity & Turbidiometer \\
Nitrate/Nitrite & EPA 353.1 \\
Metals & ICP \\
\hline
\end{tabular}

Lists of sampling procedures for surface water and groundwater are contained in the QAPjP (Sect. 3.3) (Table 11); information on field instrument uses and detection limits is given in Table 13. 


\section{7 \\ BIOREACTOR: \\ HIGH-RATE TREATMENT OF CONTAMINATED WATER}

INFLOW OF

CONTAMINATED WATER

BAFFLES

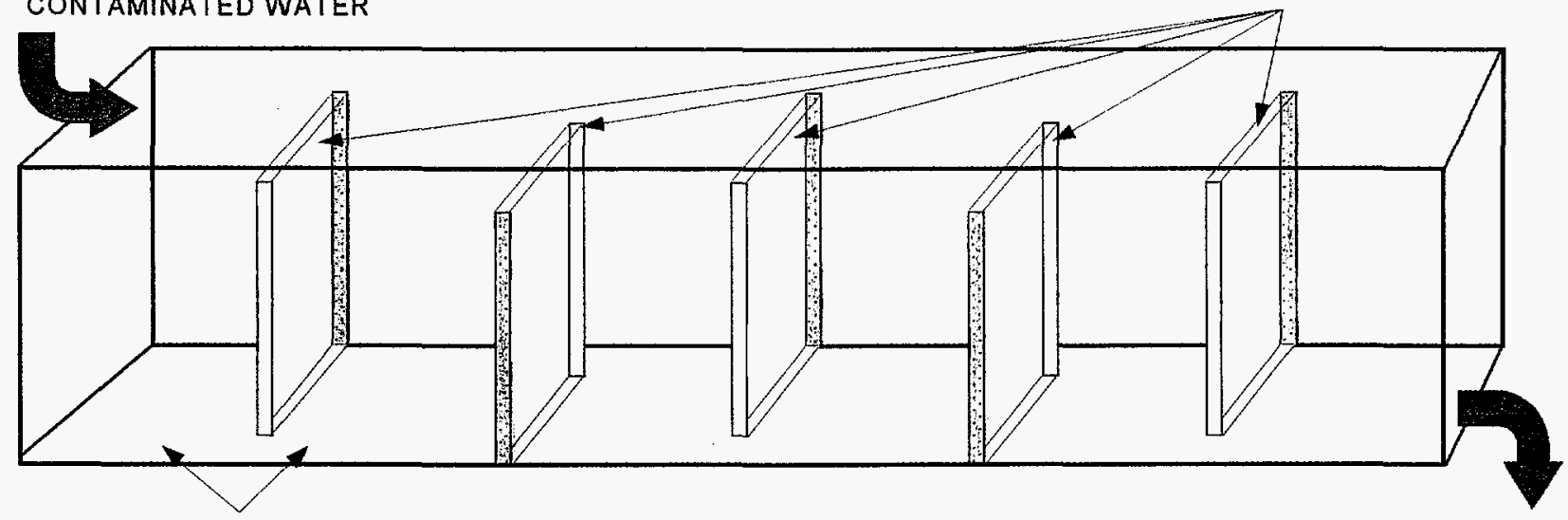

SPACES BETWEEN BAFFLES

TO SUSPEND SHEETS OF IMMOBILIZED BIOMAT TM

OUTFLOW

TREATED

WATER

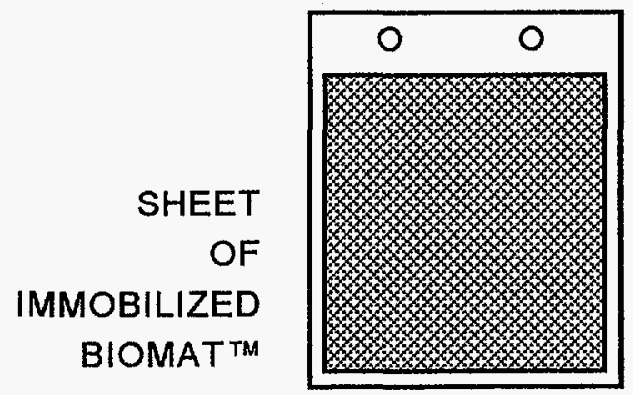

TOP VIEW OF BIOREACTOR

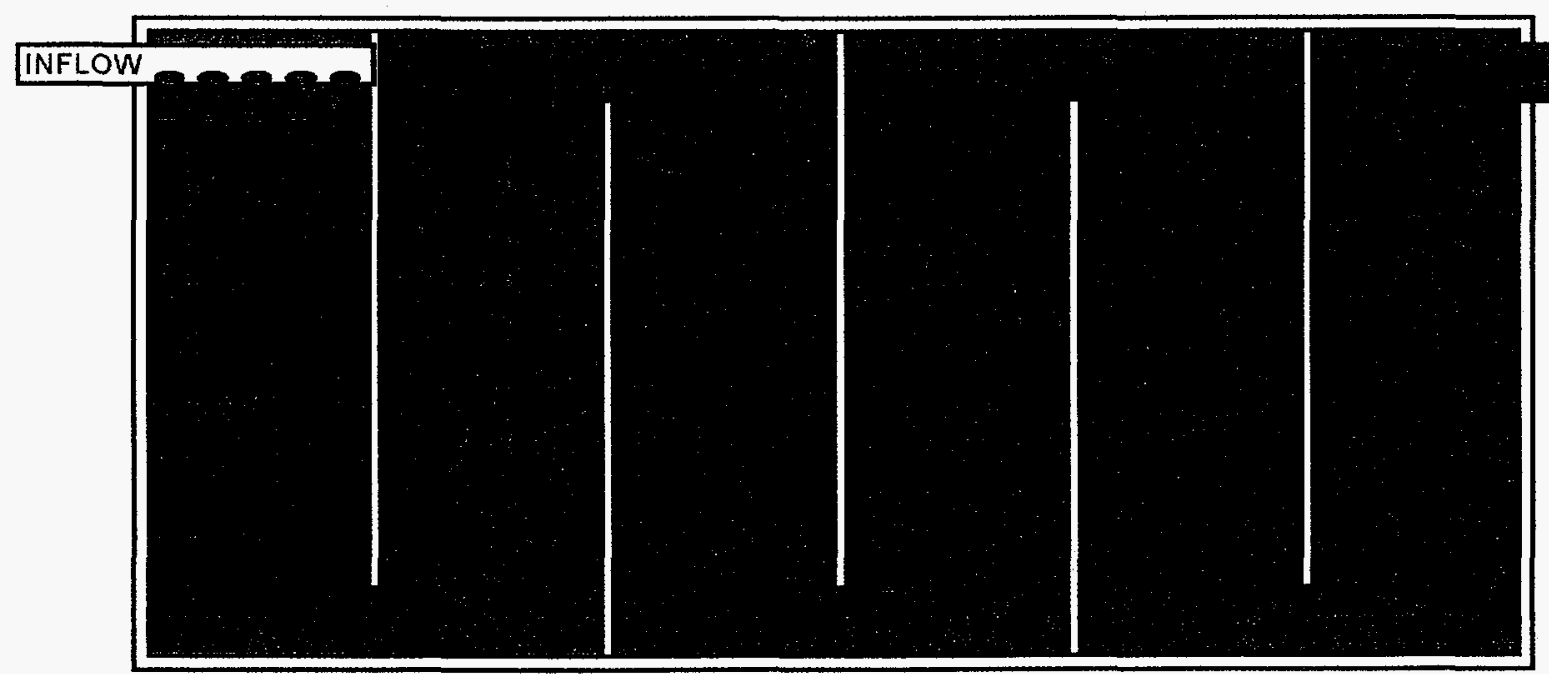

Fig. 3. New algal bioreactor figure from MAT'S. 


\subsubsection{Algal Mats Field QC}

QC samples will be collected at a frequency identified in the QAPjP to assess the quality of sampling. Field QC samples include blanks, rinsates, and duplicates. Equipment rinsates will be collected at a rate of approximately $5 \%$ of the samples collected and field duplicates will be collected at a frequency of $10 \%$ of the samples collected. The number of QC samples for the algal mats task is listed in Table 4.

Table 4. Analyte groups and number of samples for algal mat reactor

\begin{tabular}{lccccc}
\hline \multicolumn{1}{c}{ Analyte } & $\begin{array}{c}\text { Number } \\
\text { of feed samples }\end{array}$ & $\begin{array}{c}\text { Number of } \\
\text { effluent samples }\end{array}$ & $\begin{array}{c}\text { Duplicated } \\
\text { samples }\end{array}$ & $\begin{array}{c}\text { Rinsate } \\
\text { samples }\end{array}$ & Total \\
\hline Field process ${ }^{a}$ & 48 & 48 & NA & NA & 96 \\
Metals & & 24 & 3 & 1 & 28 \\
Nitrate & 24 & 3 & 1 & 28 \\
\hline
\end{tabular}

a Field measurements will be made twice weekly for $\mathrm{pH}$, Eh, conductivity, temperature, and nitrate.

\subsection{WETLANDS}

The objective of wetlands sampling is to determine the denitrifying capacity and metal uptake capacity of mature wetlands systems operating without supplemental carbon. In addition, testing will determine the relative uptake of metals into the solid plant mass so that accumulation capacity can be predicted over longer treatment periods. The results of this work will provide the basis for design of constructed treatment wetlands to address the contaminated surface water tributaries.

Activities in this task will focus on re-establishing flow through the wetlands and documenting uranium and metal uptake during the spring and summer season. During this period, field data $(\mathrm{pH}$, oxidation-reduction potential, conductivity, temperature) will be collected weekly, and water samples will be collected bi-weekly and archived. Monthly samples will be submitted for metals and nitrate/nitrite analysis. Additional archived samples will be submitted based on technical observations of performance. At the beginning and end of the program, solid root mass will be collected and analyzed for metal uptake. The program is expected to continue for 28 weeks to allow testing during both dry and wet seasons.

\subsubsection{Wetlands Field Sampling}

Figure 4 shows the configuration of the wetlands including sampling locations. Table 5 lists the analyte groups and Table 6 lists the number of samples anticipated for each analyte group. Lists of individual analytes within each analyte group are contained in the QAPjP (Chap. 3 of this document) and include information on analytical method, detection limits, container sizes, preservatives, and analytical DQOs (Tables 9, 10, and 12). 
Table 5. Analyte groups for wetlands

\begin{tabular}{cc}
\hline Analyte & Method \\
\hline Conductivity & EPA 120.1 \\
pH & EPA 150.1 \\
Temperature & EPA 170.1 \\
Eh & Electrometric \\
Dissolved oxygen & EPA 360.1 \\
Turbidity & Turbidiometer \\
Nitrate/Nitrite & EPA 353.1 \\
Metals & ICP \\
\hline
\end{tabular}

Table 6. Analyte groups and number of samples for wetlands

\begin{tabular}{lrrrrr}
\hline Analyte & $\begin{array}{c}\text { Number } \\
\text { of feed } \\
\text { samples }\end{array}$ & $\begin{array}{c}\text { Number of } \\
\text { effluent } \\
\text { samples }\end{array}$ & $\begin{array}{c}\text { Duplicated } \\
\text { samples }\end{array}$ & $\begin{array}{c}\text { Rinsate } \\
\text { samples }\end{array}$ & Total \\
\hline Field measurements & 84 & 84 & NA & NA & 168 \\
Metals & 30 & 30 & 6 & 3 & 69 \\
\hline
\end{tabular}

Lists of sampling procedures for surface water and groundwater are contained in the QAPjP (Sect. 3.3) (Table 11); information on field instrument uses and detection limits is given in Table 13 .

\subsubsection{Wetlands Field QC}

QC samples will be collected at a frequency identified in the QAPjP to assess the quality of sampling. Field QC samples include blanks, rinsates, and duplicates. Equipment rinsates will be collected at a rate of approximately $5 \%$ of the samples collected, and field duplicates will be collected at a frequency of $10 \%$ of the samples collected. The number of QC samples for the wetlands task is listed in Table 6. 


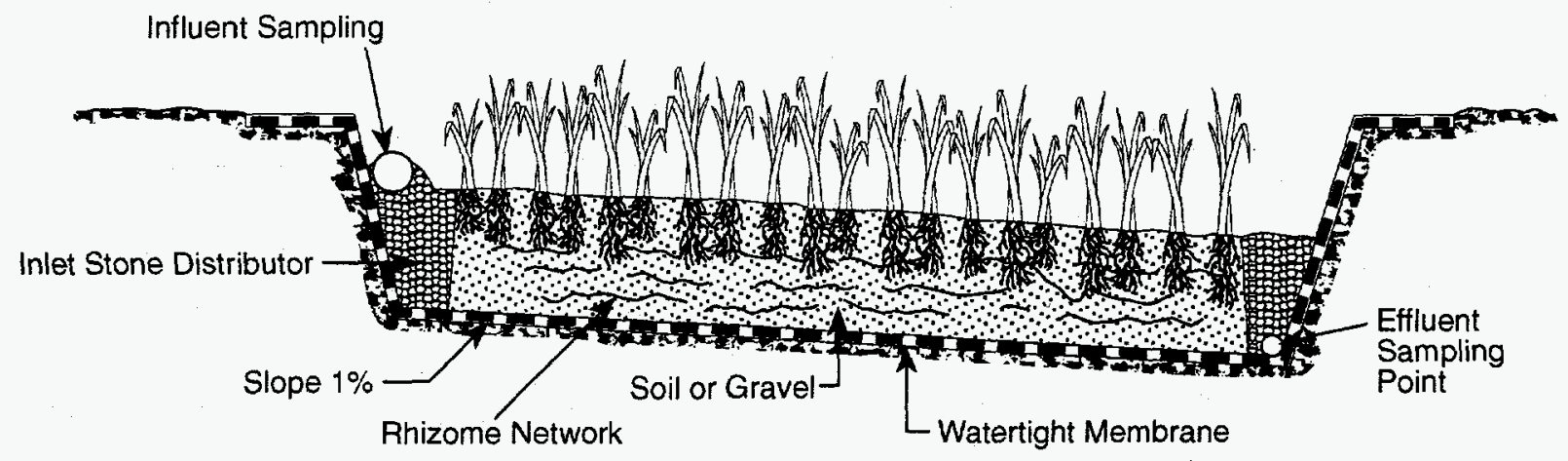

Fig. 4. Configuration of the wetlands and sampling locations. 


\section{QUALITY ASSURANCE PROJECT PLAN}

This QAPjP has been developed for use in the sample collection and sample analysis activities during the BCV Treatability Study to ensure that appropriate levels of quality assurance (QA) and QC are achieved. This QAPjP defines procedures that will be followed in the collection, custody, and handling of data used in the project. These procedures are intended to define the methods applied to achieve the QA/QC goals established for the BCV Treatability Study.

This document further establishes QA requirements and responsibilities applicable to project participants and establishes methods through which project participants implement the requirements of the project. Where no appropriate procedure exists, this QAPjP requires that one be developed by a cognizant individual(s) or organization(s).

All QA/QC procedures will be in accordance with applicable professional technical standards, U.S. Environmental Protection Agency (EPA) requirements, government regulations, U.S. Department of Energy (DOE) Orders, Lockheed Martin Energy Systems, Inc. (Energy Systems) procedures, guidelines, reassessment goals, and requirements. This section has been prepared to meet the requirements of the Environmental Restoration Quality Program Plan [ES/ER/TM-4/R4 (Energy Systems 1994)] and its guidance document, Interim Guidelines and Specifications for Preparing Quality Assurance Project Plans [EPA-600/4-83-004, QAMS-005/80 (Stanley and Verner 1983)]. Table 7 lists the location of the elements required by QAMS-005/80 and ES/ER/TM-4/R4 in this SAP and QAPjP.

\subsection{PROJECT ORGANIZATION}

The BCV Treatability Study is funded through the Energy Systems Environmental Management and Enrichment Facilities (EMEF) Program with management and operations for the project directed through the Energy Systems EMEF Division. The project is providing data to be used by Energy Systems, DOE, EPA, and Tennessee Department of Environment and Conservation (TDEC) personnel. Organization of this project is depicted in Fig. 5. Key project personnel are listed in Table 8.

\subsubsection{Project Personnel Responsibilities}

Sampling and analytical activities will be implemented throughout the life of the project to ensure that quality objectives are met. All project personnel are responsible for QA/QC processes during implementation of this SAP.

\subsubsection{SAIC BCV Treatability Study Project Manager}

The Project Manager will report project progress and results to the EMEF Program Manager and Program Manager and is responsible for

- ensuring that appropriate QA/QC requirements are included in subcontracts and that subcontractor technical commitments are met; 
Table 7. Cross reference of EPA QAMS 005/80 and ES/ER/TM-4/R4 elements with the BCV Treatability Study

\begin{tabular}{|c|c|c|c|c|c|}
\hline \multicolumn{2}{|r|}{ EPA QAMS 005/80 } & \multicolumn{2}{|c|}{ ES/ER/TM-4/R4 element } & \multicolumn{2}{|r|}{ Location within Work Plan } \\
\hline 1. & Title page & 4.1 .2 & $\begin{array}{l}\text { QAPjP Document } \\
\text { Control }\end{array}$ & Title $\mathrm{F}$ & page \\
\hline 2. & Table of Contents & 4.1 .2 & $\begin{array}{l}\text { QAPjP Document } \\
\text { Control }\end{array}$ & Table & of Contents \\
\hline 3. & Project Description & 1.6.2.2.1 & Project Description & Chapt & ters $1-2$ \\
\hline 4. & $\begin{array}{l}\text { Project Organization } \\
\text { and Responsibility }\end{array}$ & 1.5 & $\begin{array}{l}\text { Organization and Program } \\
\text { Responsibilities }\end{array}$ & 3.1 & Project Organization \\
\hline 5. & QA Objectives & 6.1 .1 & $\begin{array}{l}\text { QA Objectives for } \\
\text { Measurement Data }\end{array}$ & 3.2 & QA Objectives for Data Measurement \\
\hline 6. & Sampling Procedure & $\begin{array}{l}5.3 .1 \\
6.1 .2\end{array}$ & $\begin{array}{l}\text { Sampling Procedure } \\
\text { Sampling Control }\end{array}$ & 3.3 & Sample Collection Procedures \\
\hline 7. & Sample Custody & 5.3 .2 & Sample Custody & 3.4 & Sample Custody \\
\hline 8. & $\begin{array}{l}\text { Calibration } \\
\text { Procedures and } \\
\text { Frequency }\end{array}$ & 5.4 & $\begin{array}{l}\text { Control of Measuring and } \\
\text { Testing Equipment }\end{array}$ & 3.5 & Calibration Procedures \\
\hline 9. & Analytical Procedures & $\begin{array}{l}5.3 .3 \\
6.1 .6\end{array}$ & $\begin{array}{l}\text { Analytical Procedures } \\
\text { Specific Routine } \\
\text { Procedures }\end{array}$ & $\begin{array}{l}3.6 \\
3.11\end{array}$ & $\begin{array}{l}\text { Analytical Procedures } \\
\text { Specific Routine Procedures }\end{array}$ \\
\hline 10. & $\begin{array}{l}\text { Data Reduction, } \\
\text { Validation and } \\
\text { Reporting }\end{array}$ & 6.1 .3 & Analytical Control & $\begin{array}{l}3.7 \\
3.8\end{array}$ & $\begin{array}{l}\text { Data Reduction, Validation and Reporting } \\
\text { QC Checks }\end{array}$ \\
\hline 11. & Internal QC Checks & 8.2 & $\begin{array}{l}\text { Inspection, Testing, and } \\
\text { Operating Status }\end{array}$ & 3.10 & Preventive Maintenance Procedures/Schedules \\
\hline 12. & $\begin{array}{l}\text { Performance and System } \\
\text { Audits }\end{array}$ & $\begin{array}{l}9.3 \\
9.4 \\
10.1 \\
10.2 \\
10.3\end{array}$ & $\begin{array}{l}\text { Field Surveillance } \\
\text { Readiness Reviews } \\
\text { ER Program Audits } \\
\text { Analytical Laboratory Audits } \\
\text { Surveillance }\end{array}$ & 3.9 & Audits and Surveillance \\
\hline 13. & Preventive Maintenance & 5.4 & $\begin{array}{l}\text { Control of Measuring and } \\
\text { Testing Equipment }\end{array}$ & 3.10 & Preventive Maintenance Procedures/Schedules \\
\hline 14. & $\begin{array}{l}\text { Specific Routine } \\
\text { Procedures Used to } \\
\text { Assess Data Precision, } \\
\text { Accuracy, } \\
\text { Representativeness, } \\
\text { Completeness, and } \\
\text { Comparability }\end{array}$ & 6.1 .4 & $\begin{array}{l}\text { Specific Routine } \\
\text { Procedures }\end{array}$ & 3.11 & Specific Routine Procedures \\
\hline 15. & Corrective Actions & $\begin{array}{l}3.2 \\
3.3\end{array}$ & $\begin{array}{l}\text { Control of Nonconforming } \\
\text { Items } \\
\text { Corrective Actions }\end{array}$ & 3.12 & Corrective Action \\
\hline 16. & $\begin{array}{l}\text { QA Reports to } \\
\text { Management }\end{array}$ & $\begin{array}{l}1.6 .2 .2 .2 \\
3.2\end{array}$ & $\begin{array}{l}\text { QA Reports to Management } \\
\text { Control of Nonconforming } \\
\text { Items }\end{array}$ & 3.13 & QA Reports \\
\hline
\end{tabular}




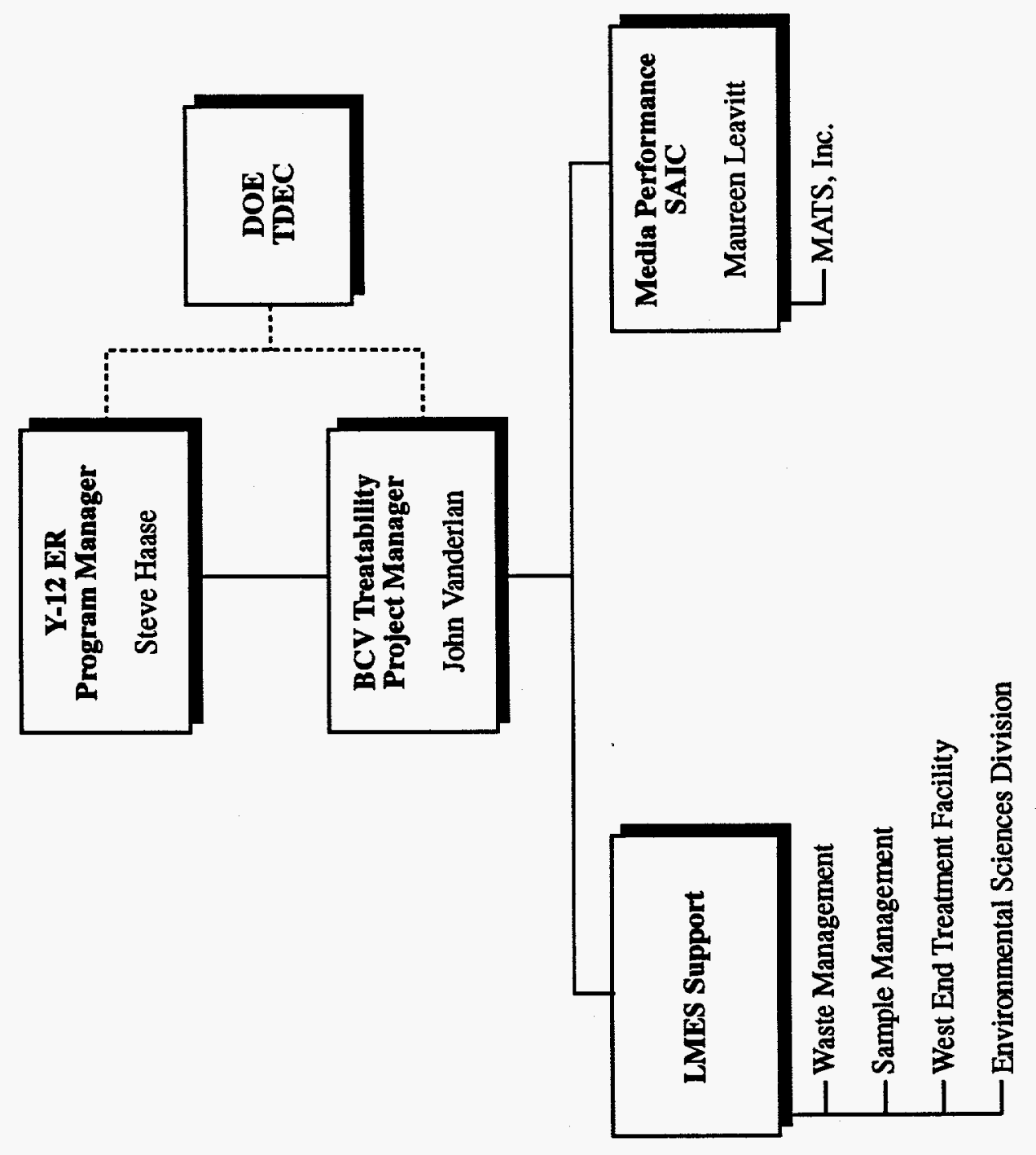

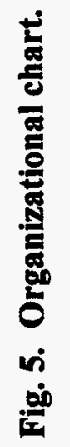


Table 8. Key project personnel and affiliations

\begin{tabular}{llll}
\hline \multicolumn{1}{c}{ Responsibility } & Name & $\begin{array}{c}\text { Telephone/ } \\
\text { Fax }\end{array}$ & e-Mail \\
\hline DOE Program Manager & David Adler & $576-9634$ & \\
DOE QA Specialist & David Carden & $576-9262$ & cardendm@oro.doe.gov \\
& & $576-6074$ & \\
Energy Systems Project & John Vanderlan & $576-2745$ & vanderlanjh@ornl.gov \\
Manager & & $574-1660$ & \\
Energy Systems EMEF & Thomas Koepp & $576-8057$ & tk7@ornl.gov \\
QA Specialist & & $574-9538$ & \\
Energy Systems EMEF & Larry May & $576-4018$ & mayle@ornl.gov \\
Health and Safety & & $574-9538$ & \\
Manager & & & \\
Energy Systems EMEF & Jeff Henderson & $241-2410$ & hendersonjc@ornl.gov \\
Waste Coordinator & & $241-2533$ & \\
SAIC Project Manager & Maureen Leavitt & $481-4614$ & leavittm@orjt1.saic.com \\
& & $481-8797$ & \\
SAIC QA Specialist & Nile Luedtke & $481-8751$ & luedtken@orjt1.saic.com \\
& & $481-1198$ & daviss@orjt1.saic.com \\
SAIC Health and Safety & Steve Davis & $481-4755$ & \\
SAIC Field Operations & Dan Thompson & $481-4750$ & \\
Manager & & $481-8797$ & \\
\hline
\end{tabular}

- incorporating the appropriate QA requirements for this project in all sampling and analytical activities;

- consulting with the QA Specialist on all quality-related matters;

- investigating quality problems during sampling operations, determining their root cause, proposing solutions, implementing corrective actions, and obtaining the concurrence of the QA Specialist on the appropriateness of the corrective action;

- initiating stop-work actions when conditions or procedures adverse to quality warrant immediate action; and

- conducting operational readiness reviews according to ER/C-P1610, "Conducting Project Readiness Reviews." 


\subsubsection{SAIC QA Specialist}

The QA Specialist reports to the Program Manager and the Project Manager and is responsible for

- helping the Project Manager establish and implement the QA measures outlined in this SAP;

- evaluating the effectiveness of QA activities through audits and surveillance and reporting results to the QA Manager and Project Manager;

- providing guidance to resolve quality problems encountered during sampling and/or decontamination operations and ensuring that corrective action is taken and appropriately documented;

- participating in the operational readiness review; and

- initiating stop-work actions when the severity of conditions adverse to quality warrants immediate action.

\subsubsection{SAIC Field Operations Manager}

The Field Operations Manager will oversee environmental sampling and will be responsible for site accessibility, safety, and QA measures, delegating specific responsibilities in areas to other members of the sampling team, specifically the Field Operations Manager (FOM). The FOM will

- coordinate on-site operations, including logistics;

- interface with site and project personnel;

- $\quad$ assist the Site Health and Safety (H\&S) Officer when necessary;

- participate in on-site sampling activities;

- determine in-field procedural variances necessary to respond to site-specific conditions and obtain concurrence of the Project Manager;

- document and report to the Project Manager unforeseen site-specific changes and corrective actions.

- ensuring the QA requirements as outlined in this SAP are adhered to;

- ensuring that sampling and decontamination procedures are effectively implemented;

- ensuring that all applicable state and federal codes, standards, and regulations are appropriately specified and effectively implemented; and

- initiating stop-work actions when conditions or procedures adverse to quality warrant immediate action. 


\subsubsection{Sampling Team Personnel}

The responsibilities of the sampling teams are

- ensuring the QA requirements as outlined in this SAP for sampling operations and decontamination are adhered to;

- ensuring that appropriate $\mathrm{QA} / \mathrm{QC}$ requirements and technical commitments as outlined in the respective subcontractor contracts are met;

- interfacing with the FOM on all quality-related matters; and

- initiating stop-work actions when conditions or procedures adverse to quality warrant immediate action.

\subsubsection{Laboratory Coordination}

A critical link with respect to sample analysis revolves around the analytical laboratory support services. Laboratory analysis for this project will be arranged through the Oak Ridge Sample Management Office (OR SMO) as administered by the Analytical Services Organization of Energy Systems. The SAIC QA Specialist will interface with the OR SMO regarding contract statements of work, selection, oversight, and coordination of analytical support to this project.

SMO responsibilities will include

- developing and disseminating statements of work for analytical services;

- selecting appropriate analytical facilities to perform the required project analysis;

- identifying appropriate analytical protocols to the selected laboratory organization(s);

- identifying technical and quality standards for the requested analytical services to the selected laboratory organization;

- negotiating analytical costs and schedule for provision of analytical services, with oversight to ensure costs and schedules are maintained;

- overseeing and assessing laboratory(s) systems to ensure compliance with project quality and technical standards;

- receiving and disseminating laboratory analytical data deliverables to SAIC and EMEF Project Management; and

- verifying laboratory data deliverables relative to laboratory payment. 
SAIC responsibilities will include

- reviewing statements of work for analytical services;

- defining appropriate analytical protocols required by the project;

- defining technical and quality standards required by the project;

- coordinating with the laboratory through the SMO during sample collection and shipment;

- validating hardcopy and electronic data deliverables from the laboratory; and

- managing data and databases for all project information.

\subsection{QA OBJECTIVES FOR DATA MEASUREMENT}

QA objectives for data collection and analysis are developed as DQOs for this project. The DQOs are defined in Chaps. 1 through 3 of this SAP.

General QA objectives for the analytical data are as follows:

- data generated will withstand scientific and technical scrutiny;

- data will be generated using appropriate procedures for analysis, chain-of-custody, data documentation, and reporting; and

- data will be of known precision, accuracy, and sensitivity.

Goals for data precision, accuracy, and completeness are presented in Table 9, while sensitivity goals have been identified in Table 10 .

While the laboratory for this project has not yet been specified, the QC criteria included here should be considered minimum requirements. When the laboratory or laboratories have been specified, the QC requirements defined here will be communicated to those facilities in analytical services statements of work. Any necessary changes to these requirements will be documented and approved through the project field change order (FCO) system. Requirements for analytical documentation by the selected laboratory(s) for this project will be similar to the documentation requirements outlined under the EPA Contract Laboratory Program (CLP) protocol. These requirements are identified throughout this Laboratory QAPjP. Analyses will be scheduled according to site investigation needs and will be consistent with sample analytical holding times. These requirements will be included in any contractual agreement between OR SMO and the laboratory(s) used for the BCV Treatability Study.

QA objectives for all analytical data are to obtain reproducible, precise, and accurate measurements consistent with the intended use of the data and the limitations of the sampling and analytical procedures. The purpose of quality control is (1) to screen out data of unacceptable precision, accuracy, or sensitivity, and (2) to document the viability of the data used to accomplish the objectives of this project. All analyses for this project will require analytical QC to be implemented, documented, and reported as part of the data deliverables. Analytical data will be reported in accordance with a standard data deliverable as defined in this QAPjP and with QC procedures consistent with the EPA CLP process and Energy Systems' "Analytical Services Master Specifications." 
Table 9. Surface water/groundwater DQO summary for BCV Treatability Study, Oak Ridge, Tennessee

\begin{tabular}{|c|c|c|c|c|c|c|}
\hline Data use & Sample type & Analytical method & $\begin{array}{l}\text { Precision } \\
\text { field dups }\end{array}$ & $\begin{array}{l}\text { RPD* lab } \\
\text { dups }\end{array}$ & $\begin{array}{l}\text { Analytical accuracy } \\
\text { (MS recovery) }\end{array}$ & Completeness \\
\hline \multirow{6}{*}{$\begin{array}{l}\text { Determination of } \\
\text { basic water } \\
\text { characteristics }\end{array}$} & Discrete & $\begin{array}{l}\text { EPA-120.1 } \\
\text { conductivity }\end{array}$ & $<10 \mathrm{RPD}$ & NA & $+/-10 \mu \mathrm{mhos} / \mathrm{cm}$ & $95 \%$ \\
\hline & & EPA-150.1 pH & $<10$ RPD & NA & $+/-0.1$ s.u. & $95 \%$ \\
\hline & & $\begin{array}{l}\text { EPA-170.1 } \\
\text { temperature }\end{array}$ & $<10 \mathrm{RPD}$ & NA & $+/-1^{\circ} \mathrm{C}$ & $95 \%$ \\
\hline & & $\begin{array}{l}\text { Turbidometer } \\
\text { turbidity }\end{array}$ & $<10 \mathrm{RPD}$ & NA & $+1-2$ NTU & $95 \%$ \\
\hline & & $\begin{array}{l}\text { EPA-360.1 } \\
\text { dissolved oxygen }\end{array}$ & $<10 \mathrm{RPD}$ & NA & $+1-0.5 \mathrm{mg} / \mathrm{L}$ & $95 \%$ \\
\hline & & $\begin{array}{l}\text { Electrometric Ox. } \\
\text { Red. Poten. }\end{array}$ & $<10 \mathrm{RPD}$ & NA & $+/-50 \mathrm{mV}$ & $95 \%$ \\
\hline \multirow[t]{2}{*}{$\begin{array}{l}\text { Rapid Screening } \\
\text { Determination }\end{array}$} & $\begin{array}{l}\text { Discrete or } \\
\text { composite }\end{array}$ & $\begin{array}{l}\text { HACH Method } \\
\text { Nitrate }\end{array}$ & $<40$ RPD & $<30$ RPD & $50-150 \%$ recovery & $95 \%$ \\
\hline & & ICP screen Total U & $<40 \mathrm{RPD}$ & $<30$ RPD & $50-150 \%$ recovery & $95 \%$ \\
\hline \multirow{7}{*}{$\begin{array}{l}\text { Confirmation of } \\
\text { contamination } \\
\text { extent }\end{array}$} & Discrete & $\begin{array}{l}\text { CLP OLM03.1 } \\
\text { VOCs }\end{array}$ & $<30$ RPD & $<20 \mathrm{RPD}$ & $50-150 \%$ recovery & $90 \%$ \\
\hline & $\begin{array}{l}\text { Discrete or } \\
\text { composite }\end{array}$ & $\begin{array}{l}\text { CLP ILM04.0 } \\
\text { Metals }\end{array}$ & $<30 \mathrm{RPD}$ & $<20 \mathrm{RPD}$ & $75-125 \%$ recovery & $90 \%$ \\
\hline & & $\begin{array}{l}\text { EPA } 310.1 \\
\text { alkalinity }\end{array}$ & $<30 \mathrm{RPD}$ & $<20 \mathrm{RPD}$ & $70-130 \%$ recovery & $90 \%$ \\
\hline & & $\begin{array}{l}\text { EPA } 160.1 / 160.2 \\
\text { TSS/TDS }\end{array}$ & $<30 \mathrm{RPD}$ & $<20 \mathrm{RPD}$ & $70-130 \%$ recovery & $90 \%$ \\
\hline & & $\begin{array}{l}\text { Alpha Spec. U \& } \\
\text { Th isotopic }\end{array}$ & $<60 \mathrm{RPD}$ & $<40$ RPD & $50-150 \%$ recovery & $90 \%$ \\
\hline & & Liq. Scint. Tc-99 & $<60$ RPD & $<40$ RPD & $50-150 \%$ recovery & $90 \%$ \\
\hline & & $\begin{array}{l}\text { Proportional Ct. Sr } \\
89 / 90\end{array}$ & $<60$ RPD & $<40$ RPD & $50-150 \%$ recovery & $90 \%$ \\
\hline
\end{tabular}

a $\mathrm{RPD}=$ relative percent difference, at values within five times the reporting level comparison is acceptable if values are plus or minus twice the reporting level. 
Table 10. Analytical methods, parameters, and project quantitation limits for BCV Treatability Study Investigations, Oak Ridge, Tennessee

\begin{tabular}{|c|c|c|}
\hline & Analytical methods & Project quantitation levels \\
\hline Parameters & Water & $\begin{array}{l}\text { Water } \\
(\mu \mathrm{g} / \mathrm{L})\end{array}$ \\
\hline Volatile Organic Compounds (VOCs) & EPA CLP OLM03.1 ${ }^{\mathrm{b}}$ & \\
\hline Chloromethane & & 10 \\
\hline Bromomethane & & 10 \\
\hline Vinyl chloride & & 2 \\
\hline Chloroethane & & 10 \\
\hline Methylene chloride & & 5 \\
\hline Acetone & & 10 \\
\hline Carbon disulfide & & 5 \\
\hline 1,1-Dichloroethene & & 5 \\
\hline 1,1-Dichloroethane & & 5 \\
\hline 1,2-Dichloroethene (total) & & 5 \\
\hline Chloroform & & 5 \\
\hline 1,2-Dichloroethane & & 5 \\
\hline 2-Butanone & & 10 \\
\hline 1,1,1-Trichloroethane & & 5 \\
\hline Carbon tetrachloride & & 5 \\
\hline Bromodichloromethane & & 5 \\
\hline 1,2-Dichloropropane & & 5 \\
\hline cis-1,3-Dichloropropene & & 5 \\
\hline Trichloroethene & & 5 \\
\hline Dibromochloromethane & & 5 \\
\hline 1,1,2-Trichloroethane & & 5 \\
\hline Benzene & & 5 \\
\hline trans-1,3-Dichloropropene & & 5 \\
\hline Tribromomethane & & 5 \\
\hline 4-Methyl-2-pentanone & & 10 \\
\hline 2-Hexanone & & 10 \\
\hline Tetrachloroethene & & 5 \\
\hline Toluene & & 2 \\
\hline
\end{tabular}


Table 10 (continued)

\begin{tabular}{|c|c|c|}
\hline & Analytical methods & Project quantitation levels ${ }^{\mathrm{a}}$ \\
\hline Parameters & Water & $\begin{array}{l}\text { Water } \\
(\mu \mathrm{g} / \mathrm{L})\end{array}$ \\
\hline 1,1,2,2-Tetrachloroethane & & 5 \\
\hline Chlorobenzene & & 5 \\
\hline Ethylbenzene & & 5 \\
\hline Styrene & & 5 \\
\hline Xylenes (total) & & 5 \\
\hline \multicolumn{3}{|l|}{ Additional Compounds: } \\
\hline Trichlorotrifluoroethane & & 10 \\
\hline PCBs & EPA CLP OLM03.1 ${ }^{\mathrm{b}}$ & \\
\hline Arochlor-1016 & & 0.5 \\
\hline Arochlor-1221 & & 0.5 \\
\hline Arochlor-1232 & & 0.5 \\
\hline Arochlor-1242 & & 0.5 \\
\hline Arochlor-1248 & & 0.5 \\
\hline Arochlor-1254 & & 0.5 \\
\hline Arochlor- 1260 & & 0.5 \\
\hline $\begin{array}{l}\text { Metals } \\
\text { (Target Analyte List plus) }\end{array}$ & EPA CLP ILM04.0 ${ }^{c}$ & \\
\hline Aluminum & & 50 \\
\hline Antimony & & 6 \\
\hline Arsenic & & 5 \\
\hline Barium & & 5 \\
\hline Beryllium & & 1 \\
\hline Cadmium & & 1 \\
\hline Calcium & & 50 \\
\hline Chromium & & 5 \\
\hline Cobalt & & 5 \\
\hline Copper & & 5 \\
\hline Iron & & 10 \\
\hline Lead & & 3 \\
\hline
\end{tabular}


Table 10 (continued)

\begin{tabular}{|c|c|c|}
\hline & Analytical methods & Project quantitation levels ${ }^{\mathrm{a}}$ \\
\hline Parameters & Water & $\begin{array}{l}\text { Water } \\
(\mu \mathrm{g} / \mathrm{L})\end{array}$ \\
\hline Magnesium & & 50 \\
\hline Manganese & & 5 \\
\hline Mercury (CVAA) & & 0.2 \\
\hline Nickel & & 10 \\
\hline Potassium & & 50 \\
\hline Selenium & & 5 \\
\hline Silver & & 5 \\
\hline Sodium & & 50 \\
\hline Thallium & & 2 \\
\hline Vanadium & & 10 \\
\hline Zinc & & 5 \\
\hline \multicolumn{3}{|l|}{ Additional metals: } \\
\hline Boron & & 10 \\
\hline Lithium & & 10 \\
\hline Molybdenum & & 10 \\
\hline Uranium & & 50 \\
\hline Anions \& Water Quality Parameters ${ }^{d}$ & & $(\mathrm{mg} / \mathrm{L})$ \\
\hline Chloride & EPA 300.0 & 1 \\
\hline Bromide & EPA 300.0 & 0.2 \\
\hline Fluoride & EPA 300.0 & 0.1 \\
\hline Sulfate & EPA 300.0 & 5 \\
\hline Phosphate & EPA 365.2 & 0.1 \\
\hline Alkalinity $\left(\mathrm{CO}_{3}, \mathrm{HCO}_{3}\right)$ & EPA 310.1 & NA \\
\hline Nitrate/Nitrite & EPA 353.1 & 0.2 \\
\hline Total Suspended Solids (TSS) & EPA 160.2 & 10 \\
\hline Total Dissolved Solids (TDS) & EPA 160.1 & 10 \\
\hline Turbidity & EPA 180.1 & $1 \mathrm{NTU}$ \\
\hline Radionuclides $^{e}$ & & $(\mathrm{pCi} / \mathrm{L})$ \\
\hline Uranium-234,235,238 & Alpha Spec. & 1 \\
\hline
\end{tabular}


Table 10 (continued)

\begin{tabular}{|c|c|c|}
\hline \multirow[b]{2}{*}{ Parameters } & Analytical methods & Project quantitation levels $^{2}$ \\
\hline & Water & $\begin{array}{l}\text { Water } \\
(\mu \mathrm{g} / \mathrm{L})\end{array}$ \\
\hline Technetium-99 & Liquid Scint. & 10 \\
\hline \multicolumn{3}{|c|}{ Rapid Screening Determinations ${ }^{\prime}$} \\
\hline Nitrate & $\begin{array}{l}\text { Hach, Colorimetric Visual } \\
\text { Color Comparison }\end{array}$ & $5 \mathrm{mg} / \mathrm{L}$ \\
\hline Total Uranium & ICP Screen & $0.5 \mathrm{mg} / \mathrm{L}$ \\
\hline
\end{tabular}

a These are expected quantitation limits based on reagent grade water or a purified solid matrix. Actual quantitation limits may be higher depending upon the nature of the sample matrix. The limit reported on final laboratory reports will take into account the actual sample volume or weight, percent solids (where applicable), and the dilution factor, if any. The quantitation limits for additional analytes to this list may vary, depending upon the results of laboratory studies.

b Statement of Work for Organic Analysis, Multi-Media, Multi-Concentration, USEPA Contract Laboratory Program, OLM03.1.

- Statement of Work for Inorganic Analysis, Multi-Media, Multi-Concentration, USEPA Contract Laboratory Program, ILM04.0.

d Methods for Chemical Analysis of Water and Wastes, EPA 600/4-79-020.

e Laboratory specific procedures, which are consistent with DOE Environmental Measurements Laboratory (EML) Procedures Manual (HASL-300), will be submitted for the project files.

f Rapid Screening Determinations may be performed in the field or performed through quick turn-around laboratory analysis. Dilutions may be required to bring analytes into quantitative range. 


\subsection{SAMPLE COLLECTION PROCEDURES}

\subsubsection{Groundwater and Surface Water Sampling}

The BCV Treatability Study monitoring investigations will consist of groundwater sampling at monitoring well locations, surface water monitoring in Bear Creek, and sampling of media testing apparatus. Sampling data generated during all phases of this investigation must be of acceptable quality and must be comparable to similar environmental data. To ensure the quality and consistency of data, specific approved sample collection and handling procedures will be followed as identified in this QAPjP. The procedures to be followed during this investigation will be in accordance with the current version of Environmental Surveillance Procedures Quality Control Program, Rev. 4, ES/ESH/INT-14 (Kimbrough et al. 1994); Environmental Restoration Waste Management (ERWM) Programs Intersite Procedures Manual, ES/ER/INT-26/R1 (Energy Systems 1994); and the SAIC Field Technical Procedures Manual unless otherwise approved by Energy Systems. Basic procedures required for sampling activities, field measurements, decontamination, sample shipping, etc., are listed in Table 11. Sample locations and analyses to be performed for each location are identified in Chap. 2.

\subsubsection{Field Documentation}

An integral part of the QAPjP for the field activities will be to maintain current, accurate, and complete field records including logbooks, chain-of-custody forms (Fig. 6), and appropriate field data forms. Field logbooks shall be bound and of hardcover construction. All information pertinent to field activities will be recorded. Each page must be signed and dated. Entries in the logbooks or on the data forms will be made in water-resistant black ink and will include the information specified in Chain of Custody ER/K-I1600. Corrections must be marked out with a single line, dated, and initialed. All field records will be reviewed by a qualified field team member other than the person completing the record.

Appropriate field data forms will be prepared in bound logbooks based on the requirements of the current revisions of the Environmental Restoration Division Quality Program Plan ES/ER/TM-4/R4 (Energy Systems 1994) and the Environmental Surveillance Procedures Quality Control Program, Rev. 4, ES/ESH/INT-14 (Kimbrough et al. 1994). No blank spaces should appear on completed forms. If information requested is not applicable, the space shall be marked "N/A."

All field logbooks and field data forms will be handled and controlled in accordance with Handling and Control of Sampling Documentation (ER/K-I1607).

\subsubsection{Sample Containers and Holding Times}

The selection criteria for appropriate sample containers, sample preservatives, and holding times shall be in accordance with ESP-701, Sample Preservation and Container Materials. Types of sample containers and sample preservation methods used will be documented in the sampling logbook. Field and laboratory records will indicate the sample holding time before analysis. Sample containers and holding times are summarized in Table 12. 
Table 11. BCV Treatability Study sampling and support procedures

\section{Field Documentation:}

ESP-102, Rev. 0

ESP-501, Rev. 2

ESP-503, Rev. 0

Field Quality Control

Sample Chain of Custody

Field Logbooks and Data Forms

ERWM/ER-P2303, Rev. 0

Controlling and Documenting Field Changes to Approved FSPs

QAAP 15.1, Rev. 5

Control of Nonconforming Items and Services

Sample Preparation and Management:

ER/K-I1607, Rev. 0

ESP-401, Rev. 0

ESP-701, Rev. 0

ESP-505, Rev. 0

Surface Water Sampling:

ESP-301-1, Rev. 1

ESP-301-2, Rev. 1

ESP-301-5, Rev. 0

ESP-308-1, Rev. 0

BCVT-579, Rev. 0

Groundwater Sampling:

ESP-302-1, Rev. 1

ESP-302-2, Rev. 2

ESP-302-3, Rev. 1

ESP-302-4, Rev. 1

Field Measurements:

ESP-307-1, Rev. 1

ESP-504, Rev. 0

BCVT-910, Rev. 1
Handling and Control of Sample Documentation

Field Quality Control Samples

Sample Preservation and Container Materials

Preparing Samples and Laboratory Standards for Transport and Shipping

Liquid Sampling Using a Dipper

Sampling Liquids with an Automatic Sampler

Streamflow Measurements

Composite Procedures

Water Sampling Using the Bottle Submersion Method

Measurement of Static Water Level Elevation

Well Purging

Groundwater Sampling Using a Bailer

Groundwater Sampling Using a Pump

Waste Management/Decontamination:

ESP-105, Rev. 0

ESP-801, Rev. 0

ESP-802, Rev. 0
Waste Management

Cleaning and Decontaminating Sample Containers and Sampling Devices

Equipment Decontamination 
CHAIN OF CUSTODY RECORD

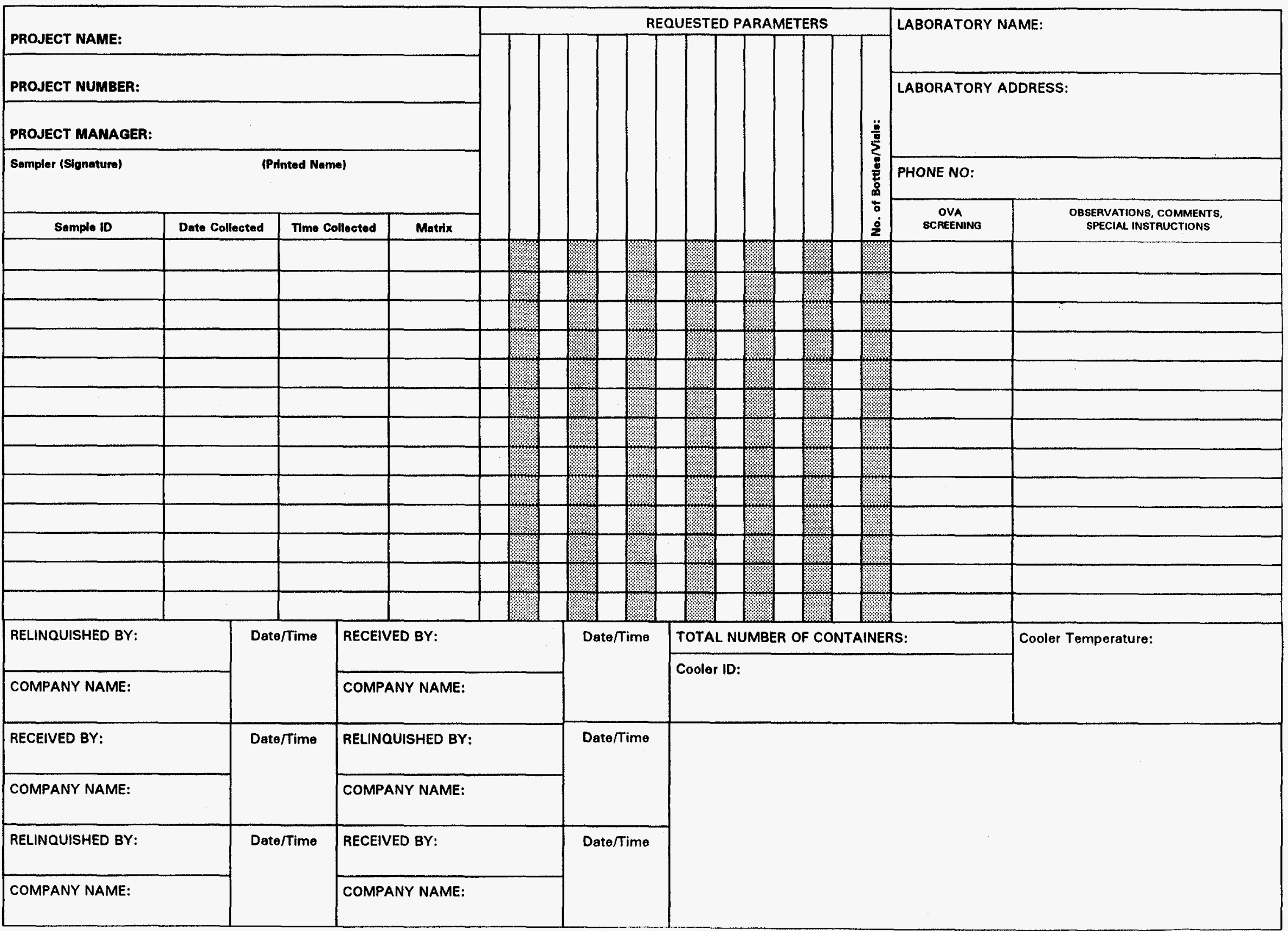

Fig. 6. Chain-of-custody record example. 
Table 12. Container recommended for BCV Treatability Study Investigations, Oak Ridge, Tennessee

\begin{tabular}{|c|c|c|c|c|}
\hline Analyte group & Container ${ }^{\circledR}$ & $\begin{array}{l}\text { Minimum } \\
\text { sample size }\end{array}$ & Preservative & Holding time \\
\hline VOCs & $\begin{array}{l}2-40 \mathrm{~mL} \text { glass vials with } \\
\text { Teflon®-lined septum } \\
\text { (no headspace) }\end{array}$ & $40 \mathrm{~mL}$ & $\begin{array}{c}\mathrm{HCL} \text { to } \mathrm{pH}<2 \\
\text { Cool, } 4^{\circ} \mathrm{C}\end{array}$ & $14 \mathrm{~d}$ \\
\hline Metals and/or $\mathrm{Hg}$ or As & 1 - L polybottle & $\begin{array}{c}500 \mathrm{~mL}, \text { metals } \\
200 \mathrm{~mL}, \mathrm{Hg}\end{array}$ & $\begin{array}{c}\mathrm{HNO}_{3} \text { to } \mathrm{pH}<2 \\
\mathrm{Cool}, 4^{\circ} \mathrm{C}\end{array}$ & $\begin{array}{l}180 \mathrm{~d} \text {, metals } \\
28 \mathrm{~d}, \mathrm{Hg}\end{array}$ \\
\hline Anions $\left(\mathrm{Cl}, \mathrm{Br}, \mathrm{F}, \mathrm{SO}_{4}\right)$ & $250 \mathrm{~mL}$ polybottle & $50 \mathrm{~mL}$ & Cool, $4^{\circ} \mathrm{C}$ & $28 \mathrm{~d}$ \\
\hline Nitrate/nitrite & $250 \mathrm{~mL}$ polybottle & $100 \mathrm{~mL}$ & $\begin{array}{c}\mathrm{H}_{2} \mathrm{SO}_{4} \text { to } \mathrm{pH}<2 \\
\mathrm{Cool}, 4^{\circ} \mathrm{C}\end{array}$ & $28 \mathrm{~d}$ \\
\hline Phosphate & $250 \mathrm{~mL}$ polybottle & $100 \mathrm{~mL}$ & $\begin{array}{c}\mathrm{H}_{2} \mathrm{SO}_{4} \text { to } \mathrm{pH}<2 \\
\text { Cool, } 4^{\circ} \mathrm{C}\end{array}$ & $28 \mathrm{~d}$ \\
\hline TDS/TSS/turbidity & $500 \mathrm{~mL}$ polybottle & $100 \mathrm{~mL}$ ea. & $\mathrm{Cool}, 4^{\circ} \mathrm{C}$ & $7 \mathrm{~d} / 7 \mathrm{~d} / 48 \mathrm{hr}$ \\
\hline Alkalinity & $250 \mathrm{~mL}$ polybottle & $100 \mathrm{~mL}$ & Cool, $4^{\circ} \mathrm{C}$ & $14 \mathrm{~d}$ \\
\hline Radionuclides & 1 gal cubitainer & $4 \mathrm{~L}$ & $\begin{array}{c}\mathrm{HNO}_{3} \text { to } \mathrm{pH}<2 \\
\mathrm{Cool}, 4^{\circ} \mathrm{C}\end{array}$ & $180 \mathrm{~d}$ \\
\hline
\end{tabular}

a One investigative water sample in 20 will require an additional 2 liters volume for the laboratory to perform appropriate laboratory QC. 


\subsubsection{Sample Packaging and Preservation}

Handling, shipping, and storage of samples and data resulting from field activities will adhere to chain-of-custody procedures and will ensure that sample integrity for analytical purposes is maintained. The procedures required to properly preserve, package, ship, handle, and store containers of environmental samples will be based on Sample Classifying, Packaging, Marking, Labeling, and Shipping for Analysis through the K-25 and Y-12 Environmental Restoration Programs, ER/C-P2303 (IAD). Field checks will be conducted and documented to ensure compliance with this procedure. Sample cooler temperature will be checked and recorded before the cooler is sealed for delivery to the analytical lab. Upon receipt of sample coolers, the lab will check and record the temperature of the cooler. To ensure that $\mathrm{QC}$ water samples are properly preserved, $\mathrm{pH}$ will be checked with $\mathrm{pH}$ strips. Field alpha and beta/gamma radiation screenings of individual samples and of coolers containing samples will be conducted to ensure compliance with U.S. Department of Transportation requirements and to ensure that Nuclear Regulatory Commission licensee limits of the labs are not exceeded.

\subsubsection{Decontamination of Equipment and Devices}

Decontamination of sample containers and sampling devices will be performed as prescribed in the Standard Operating Procedure for Decontamination (FSP Manual). Sampling equipment will be decontaminated before use and between sampling locations and intervals. Each decontamination activity will be recorded in the field logbook.

\subsubsection{Sample Identification and Traceability}

Each environmental sample collected during this project will be assigned a unique sample identifier, which will be permanently affixed to the sample container and recorded in the field logbook and chain-of-custody record. The identifiers used for samples will be established and maintained in accordance with ER/K-I1600. Identification systems will ensure traceability of samples to the appropriate source. Refer to Chaps. 2 and 4.

\subsubsection{Field Variance System}

Procedures cannot fully encompass all conditions encountered during a field investigation. Variances from the operating procedures, FSP, and/or H\&S Plan will, therefore, likely occur and must be documented on an FCO form or a nonconformance report (NCR) and be noted in the appropriate logbooks. The approach to controlling and documenting field changes will follow ER/C-P1719. If a variance is anticipated (e.g., because of a change in field instrumentation), the applicable procedure should be modified and the change noted in the field logbooks.

As appropriate, regulatory agencies will be notified of any variances that significantly affect project scope or objectives, and approval from the agencies will be obtained as necessary. Any variances from the H\&S Plan must be approved by the EMEF H\&S Officer. Copies of the FCO form will be maintained by the FOM or designee until the field work is complete and will then be forwarded to the SAIC Project Manager for inclusion in the project file. 


\subsection{SAMPLE CUSTODY}

Chain-of-custody procedures require documentation of sample possession from the time of collection to time of disposal. These procedures allow the possession and handling of samples from the time of collection through analysis and final disposal to be traced. Chain of custody shall be maintained in accordance with ER/K-I1600, Chain of Custody (FSP Procedures Manual).

Samples will be accompanied by an original completed chain-of-custody record (Fig. 6). As the samples are transferred, the present custodian and the new custodian will complete the required sections of the record as well as note any discrepancies. This chain-of-custody record will be initiated at the time of sample collection and remain with the sample from the field, while being transported to the laboratory, and into the laboratory. The laboratory will retain a copy of the record and a copy will be sent to SAIC data management personnel and Energy Systems SMO. Original chain-of-custody records will be reported with their associated analytical data deliverables.

Sample shipments will be examined immediately upon receipt by the laboratory to determine damage, loss, or inconsistencies. A sample receiving report will be completed by the laboratory indicating sample condition, cooler temperature, documentation consistency, and any problems discovered. If samples are damaged or the shipment has been otherwise compromised, the laboratory will notify the SMO by telephone immediately. Samples will be logged into the laboratory and maintained at appropriate temperatures throughout the analytical process. After appropriate information and required signatures have been added to the chain-of-custody and sample receiving report, the laboratory will return signed copies to the SMO contact within two days. The laboratory shall include a copy of the sample receiving report and documentation of the analytical log-in (project sample number, lab sample number, analysis scheduled, etc.) in this sample receiving report.

After sample receipt and throughout analysis, the laboratory will maintain custody of all samples, aliquots, resultant extracts, and digestions. Tracking and internal chain-of-custody records will be recorded by the laboratory, however, this documentation will not be required as part of the analytical deliverable. Internal chain-of-custody information will be verified during on-site audits by the OR SMO.

\subsection{CALIBRATION PROCEDURES AND FREQUENCY}

All Measuring and Testing Equipment (M\&TE) will be calibrated against certified equipment and/or standards having known valid traceability to nationally recognized standards. M\&TE shall be calibrated, adjusted, and maintained at prescribed intervals or before use. If no nationally recognized standards exist, the basis for calibration will be documented.

\subsubsection{Field Instrument Calibration Procedures and Frequency}

Field instrumentation will be calibrated according to the procedures specified in the manufacturer's operating manual or more frequently should the conditions dictate it for the particular instrument. Table 13 lists all M\&TE to be used, detection limits, and a schedule for calibration. Instrument logbooks or notebooks will be established and maintained by the cognizant field team members, the FOM, or the $\mathrm{H} \& \mathrm{~S}$ Officer, as appropriate. 
Table 13. Field instrument uses, detection limits, and calibration

\begin{tabular}{|c|c|c|c|c|}
\hline Instrument & Uses & Detection limits & Calibration & Comments \\
\hline $\begin{array}{l}\text { Radiological } \\
\text { monitoring }\end{array}$ & $\begin{array}{l}\text { Monitoring of beta-gamma } \\
\text { surface, gross gamma, alpha } \\
\text { surface contamination levels }\end{array}$ & $\begin{array}{l}\text { Daily calibration check } \\
\text { varies by equipment }\end{array}$ & $\begin{array}{l}\text { Daily source check per } \\
\text { manufacturer }\end{array}$ & $\begin{array}{l}\text { Validation labels include minimum and } \\
\text { maximum acceptable levels }\end{array}$ \\
\hline $\mathrm{pH}$ meters & Field screening of waters & N/A & $\begin{array}{l}2 \text { point with standards at } \mathrm{pH} 7.0 \\
\text { and } 4.0 \text { or } \mathrm{pH} 7.0 \text { and } 10.0 \text { daily }\end{array}$ & Accuracy is to $\pm 0.5 \mathrm{pH}$ units \\
\hline $\begin{array}{l}\text { Temperature } \\
\text { (in-line) }\end{array}$ & $\begin{array}{l}\text { Determining water } \\
\text { temperature }\end{array}$ & N/A & To manufacturer instructions & \\
\hline Conductivity meter & $\begin{array}{l}\text { Determining conductivity of } \\
\text { water }\end{array}$ & N/A & 1 point in KCL solution & $\begin{array}{l}\text { Calculations and acceptance criteria must be } \\
\text { available in the field }\end{array}$ \\
\hline $\begin{array}{l}\text { Dissolved oxygen } \\
\text { meter }\end{array}$ & $\begin{array}{l}\text { Determining amount of } \\
\text { dissolved oxygen in water }\end{array}$ & N/A & To manufacturer instructions & Calculations must be available in the field \\
\hline Redox & $\begin{array}{l}\text { Determining } \\
\text { oxidation/reduction potential } \\
\text { in water }\end{array}$ & N/A & To manufacturer instructions & \\
\hline $\begin{array}{l}\text { Turbidity meter } \\
\text { (Nephelometer) }\end{array}$ & Determining water clarity & N/A & $\begin{array}{l}\text { To manufacturer instructions } \\
\text { using triple-filtered reference } \\
\text { standard }\end{array}$ & $\begin{array}{l}\text { Accuracy is } \pm 0.01 \mathrm{NTU} \\
\text { Orientation of sample tube is critical for } \\
\text { consistent readings }\end{array}$ \\
\hline
\end{tabular}

$\mathrm{N} / \mathrm{A}=$ not applicable

NTU $=$ Nephelometric Turbidity Units 
All instruments will be maintained within factory calibration, in accordance with applicable manufacturers' recommendations and specifications described in the manufacturers' operation manuals. Daily calibration will be recorded on the Daily Instrument Calibration Check Sheet, located in the field logbook in a section dedicated to calibration and vital information about the instruments.

Implementation of rapid screening determinations for nitrate will involve the use of premeasured reagents and visual color comparisons based on manufacturer's color chambers. Daily checks should be performed in accordance with manufacturer's method instructions.

\subsubsection{Laboratory Instrument Calibration Procedures and Frequency}

All analytical instrumentation will be calibrated against certified equipment and/or standards having known valid traceability to nationally recognized standards. Instrumentation shall be calibrated, adjusted, and maintained at prescribed intervals or before use. If no nationally recognized standards exist, the basis for calibration will be documented.

Laboratory equipment will be calibrated according to the procedures specified in the analytical methods and in the operating manual for the particular instrument. Calibration frequency will be based on the analytical methods employed, type of equipment, inherent stability, manufacturer's recommendations, values given in national standards, intended use, and experience.

For volumetric laboratory measurements, Class A volumetric glassware shall be used to prepare calibration standards, bench standards, samples for analysis, etc. Class A glassware may be purchased with known accuracy per federal and ASTM specifications. For gravimetric measurements, calibration of analytical balances must be performed by trained and qualified instrument technicians using weights traceable to the National Institute of Standards and Technology (NIST) specifications.

It should be noted that other nonanalytical instrumentation (such as thermometers) must be properly maintained and calibrated. The temperatures of ovens and refrigerators used in sample handling shall be recorded and the control limits shall be defined. When these limits are not met, corrective action will be required.

\subsubsection{Calibration Failures}

Scheduled periodic calibration of equipment will not relieve personnel of the responsibility of employing properly functioning equipment. If an individual suspects an equipment malfunction, he/she should remove the device from service, initiate an NCR, tag the device so it is not inadvertently used, and notify project management. If equipment is found to be out of calibration, the appropriate project management personnel shall evaluate and document (in the instrument logbook) the validity of previous inspection or test results and the acceptability of similar equipment previously inspected or tested. The FOM or laboratory management shall ensure the devices that are out of calibration are (1) tagged or segregated from other equipment, and (2) disposed of or not used until they are calibrated. Any equipment that is consistently found to be out of calibration shall be repaired or replaced. Any such action should be recorded in the instrument logbook or notebook.

All standards used for equipment calibration will be traceable to the EPA, NIST, or a commercially available certified standard. The source of the standard used must be documented in a calibration logbook. 


\subsubsection{Calibration Records}

Calibration data will be recorded in the instrument logbook or notebook. The information shall include the date, operator, signature, and standard that was used. Records will be prepared and maintained for each piece of calibrated equipment to indicate that established calibration procedures

have been followed. Records shall be kept that demonstrate traceability of all calibration standards used in full or daily calibrations to the certified source. The appropriate project management personnel will ensure that records of calibration data are kept current. Records for field equipment used will be maintained by the FOM and the project H\&S Officer and kept in the project files. Records for laboratory equipment used will be maintained by the laboratory and will be kept with the equipment if practicable. Otherwise, they will be maintained by the laboratory QA personnel.

An appropriate unique instrument identification number or name must be assigned to each individual piece of analytical equipment and the due date of the next calibration will be attached to the equipment or documented in its equipment log. If this identification is not possible, records traceable to the equipment will be readily available for reference.

All standards used for equipment calibration will be traceable to the EPA, NIST, or a commercially available certified standard. The source of the standard used must be documented in a calibration logbook.

\subsection{ANALYTICAL PROCEDURES}

\subsubsection{Field Analytical Methods}

Water quality parameters (specific conductance, $\mathrm{Eh}, \mathrm{pH}$, dissolved oxygen, temperature) will be measured in the field during purging and sampling and will follow the BCV Treatability Study FSP Manual. Rapid screening determinations for nitrate will be conducted using Hach Corporation's premeasured unit-dose reagents for analysis of high range nitrate levels $(0$ to $50 \mathrm{mg} / \mathrm{L})$. Adjustment to this method will allow sample dilution prior to reduction and color development in order to perform analysis of higher levels of nitrate. Color comparisons will be made using either color discs or color cubes formulated by the Hach Corporation. The specific Hach methodology and dilution protocols will be established as field procedures.

\subsubsection{Laboratory Analytical Methods}

Organic, inorganic, and radiochemical analytical methods prescribed in this section for use in the project have been taken from the EPA CLP Statements of Work, other EPA procedures, and DOE manuals. The approved methods and protocols that are to be employed by the analytical laboratory are provided in

- Test Methods for Evaluating Solid Wastes, EPA SW-846;

- Methods for Chemical Analysis of Waters and Wastes Manual, EPA-600-4-79-020;

- Prescribed Procedures for Measurement of Radioactivity in Drinking Water, EPA-600/4-80-032; 
- Eastern Environmental Radiation Facility Radiochemistry Procedure Manual;

- EPA CLP SOWs for Organics and Inorganics;

- Inductively coupled plasma (ICP)/AAS Method for Trace Elements Analysis of Water and Wastes, 40 CFR 136, Appendix C;

- Methods for Determination of Organic Compounds in Finished Drinking Water and Raw Source Water, EPA, 40 CFR 141.30;

- Methods for Chemical Analysis for Municipal and Industrial Wastewater, EPA, 40 CFR 136, Appendix A;

- APHA, Standard Methods for the Analysis of Water and Wastewater; and

- Environmental Measurement Laboratory Procedures Manual, HASL-300.

The method detection limit is defined as the minimum concentration of a substance that can be measured and reported with $99 \%$ confidence that the value is greater than zero. The method detection limit actually achieved in a given analysis varies depending on instrument sensitivity and interferences. Contracts will be established with analytical laboratories to analyze environmental samples collected during this project. Each contract laboratory that analyzes samples will provide quantification limits for each constituent analyzed.

Specific analytical methods, parameters, and quantitation level goals are presented in Table 10.

In the event that analyte concentrations or sample matrices hinder analyses, the methods may be adapted to compensate for documented interferences. Specifically, sample analyses could be altered by

- adjusting the sample size prepared for analysis;

- adjusting instrument injection volumes;

- diluting or concentrating sample aliquots; or

- eliminating concentration steps prescribed.

All such adaptations of analytical procedures must be documented through FCOs or NCRs, and be clearly discussed in all associated laboratory case narratives.

\subsection{DATA REDUCTION, VERIFICATION/VALIDATION, AND REPORTING}

The data reduction will follow guidelines of CLP organic and inorganic protocols and EPA SW-846, Test Methods for Evaluating Solid Waste, Physical/Chemical Methods (EPA 1990). Generally, results must be expressed to two significant figures. Results of aqueous samples must be expressed in milligrams per liter, micrograms per liter, or picoCuries per liter.

Data reduction, verification/validation, and reporting will be in accordance with the ER Division Quality Program Plan, ES/ER/TM-4/R4 (Energy Systems 1994) and the Analytical Master Specifications, (OR SMO). Data will be entered into common standardized formats. In addition to 
following field and laboratory documentation and QA/QC procedures, data may be verified using a variety of computerized checks for reasonableness. These procedures will ensure that data are entered, encoded, manipulated in a consistent way, and available in a usable format.

\subsubsection{Field Data Reduction and Evaluation}

Data collected during field activities will be evaluated by checking the procedures used and comparing the data to previous measurements in accordance with ER/K-I1604 Field Data Validation. The SAIC QA/QC Officer or designee and the appropriate field personnel, will be responsible for checking field QC sample results to ensure that field measurement and sampling protocols have been observed. These reviews will check date and time sampled, preservation, standard operating procedures, calibration method and frequency, and chain-of-custody documentation.

Reviewers are responsible for ensuring that data reduction calculations are documented and checked by qualified personnel. Written reports including reduced and summarized data may include the raw data in appendixes. Specific calculations used for data reduction may also be included.

\subsubsection{Analytical Laboratory Data Reduction and Evaluation}

In general, the analyst will process the data either manually or by inputting the data into a computer. For manually processed data, all the steps in the computation must be provided, including equations used and the source of input parameters such as response factors, dilution factors, and calibration constants. If calculations are not performed directly on the data sheet or chromatogram, the calculations must be provided on company letterhead paper and attached to the data sheets. All pages of the calculations must be signed and dated by the analyst performing the calculations.

For data input by an analyst and processed using a computer, a copy of the input must be kept and uniquely identified with the project number and other pertinent information as necessary. The samples to which the data processing refers must be clearly stated, and the input must be signed and dated by the analyst performing the input. When processing data acquired from instrumentation, the analyst must verify that the correct project, sample numbers, calibration constants, response factors, units, and numerical values used for detection limits are present.

Upon completion of required chemical analyses, the samples will be maintained at a temperature of 4 $\mathrm{C}( \pm 2 \mathrm{EC})$ for at least two weeks after expiration of the appropriate holding time.

\subsubsection{Laboratory data review}

Laboratory review is responsible for ensuring that data reduction and calculations follow correct procedures, are documented, and are checked by qualified personnel. All information, including reduced and summarized data will be retained with the raw data. Specific calculations used for data reduction will also be included. The laboratory is responsible for maintaining comprehensive documentation for all data produced.

Once processed, data will be reviewed by the laboratory prior to delivery of the analytical data package for the following:

- appropriateness of equations employed; 
- correctness of numerical input (both hard-copy and electronic);

- numerical correctness of all calculations;

- correct interpretation of all chromatograms, spectra, digital output, etc.;

- comparability and correctness of initial and continuing calibration results;

- evaluation of all laboratory control standards (LCS);

- evaluation of all method blank results;

- evaluation of all surrogate, internal standard, or tracer results;

- sample traceability from receipt to data reporting by internal custody and tracking procedures; and

- evaluation of data deliverable completeness and legibility.

\subsubsection{Data reporting and deliverables}

The laboratory will be responsible for hard-copy deliverables as defined by OR SMO and identified in Table 14. These deliverables are considered a standard data deliverable or a "Forms-only Deliverable." Electronic data deliverables (EDD) will be submitted for each sample grouping and be consistent with the hard-copy provided. EDD formats will be arranged during laboratory procurement to provide information that can be utilized by the project database to produce an Oak Ridge Environmental Information System (OREIS) data deliverable.

\subsubsection{Data Validation Approach}

Data validation will be consistent with the specifications as outlined in Energy Systems Data Verification and Validation Procedures, 1996 (ERWM/ER-P2209, ERWM/ER-P2210, ERWM/ERP2211, ERWM/ER-P2212, and ERWM/ER-P2213) and be implemented through SAIC Data Validation Procedure TP-DM-300-7. All project data will be evaluated to ensure a complete, consistent, and usable project data set.

Data validation will be performed to ensure that the precision and accuracy of the analytical data are adequate for their intended use. Because the greatest uncertainty in a measurement is often a result of the sampling process and inherent variability in the environmental media rather than the analytical measurement, validation will be performed only to the level necessary to minimize the potential of using false positive or false negative concentrations in the decision-making process (i.e., to ensure accurate identification of detected versus nondetected compounds). This approach is consistent with the DQOs for the project.

\subsubsection{Data validation rationale}

The data validation criteria listed below have been determined as critical in the evaluation of analytical data usability. These are a subset of the Energy Systems data validation procedures that, based on analytical process knowledge, contribute significantly to the qualification and associated uncertainty of the reported results. Evaluation of this subset will allow identification of potential false positive or negative results. Because these criteria are associated with random rather than systematic error, they require evaluation throughout the analytical measurement process. They cannot be comprehensively determined by reviewing only a portion of the data. Consistent with the data quality requirements as defined in the DQOs and based on the above rationale, all project data and associated QC must be evaluated on these criteria and qualified as per the outcome of the review. The criteria by which the data will be evaluated are discussed in Sect. 3.7.3.2. 
Table 14. Summary of analytical hard-copy data deliverables

Deliverables

\section{Requirements for all methods:}

- Holding time information and methods requested

- Discussion of laboratory analysis, including any laboratory problems

Organics: Gas Chromatography (GS)/MS analysis

- Sample results, including TICs

- Surrogate recoveries

- Matrix spike/spike duplicate data

- Method blank data

- GC/MS tune

- GC/MS initial calibration data

- GC/MS continuing calibration data

- GC/MS internal standard area data

Organics: GC analysis

- Sample results

- Surrogate recoveries

- Matrix spike/spike duplicate data

- Method blank data

- Initial calibration data

- If calibration factors are used

- Calibration curve if used

- Continuing calibration data

- Positive identification (second column confirmation)

Metals

- Sample results

- Initial and continuing calibration

- Method blank

- ICP interference check sample

- Spike sample recovery

- Postdigestion spike sample recovery for ICP metals

- Postdigestion spike for GFAA

- Duplicates

- LCS

- Standard additions (when implemented)

- Holding times

- Run log
Signed chain-of-custody forms

Case narratives

CLP Form 1 or equivalent

CLP Form 2 or equivalent

CLP Form 3 or equivalent

CLP Form 4 or equivalent

CLP Form 5 or equivalent

CLP Form 6 or equivalent

CLP Form 7 or equivalent

CLP Form 8 or equivalent

CLP Form 1 or equivalent

CLP Form 2 or equivalent

CLP Form 3 or equivalent

CLP Form 4 or equivalent

CLP Form 6 or equivalent

A form listing each analyte, the concentration of each standard, the relative calibration factor, the mean calibration factor, and \%RSD

Calibration curve and correlation coefficient

CLP Form 9 or equivalent

CLP Form 10 or equivalent

CLP Form 1 or equivalent

CLP Form 2 or equivalent, dates of analyses and calibration curve, and the correlation coefficient factor

CLP Form 3 or equivalent and dates of analyses

CLP Form 4 or equivalent and dates of analyses

CLP Form $5 A$ or equivalent

CLP Form 5B or equivalent

CLP Form 5B or equivalent

CLP Form 6 or equivalent

CLP Form 7 or equivalent that includes acceptable range or window

CLP Form 8 or equivalent

CLP Form 13 or equivalent

CLP Form 14 or equivalent 
Table 14. (continued)

Method requirements

Deliverables

Wet Chemistry

- Sample results

- Matrix spike recovery

- Matrix spike duplicate or duplicate

- Method blank

- Initial calibration

- Continuing calibration check

- LCS

- Run log

Radiochemical Analysis

- Sample results

- Initial calibration

- Efficiency check

- Background determinations

- Spike recover results

- Internal standard results (tracers or carriers)

- Duplicate results

- Self-absorption factor $(\alpha, \beta)$

- Cross-talk factor $(\alpha, \beta)$

- LCS

- Run log
Report result

$\%$ Recovery

\%Recovery and \%RPD

Report results

Calibration curve and correlation coefficient

Recovery and \% difference

LCS result and control criteria

Copy of run log

Report results

Efficiency determination

\%Difference from calibration

Report results

Report results

Report results

Spike added and \%Recovery

Standard added and \%Recovery

Report results and \%RPD

Report factors

Report factors and control criteria

LCS results and control criteria

Copy of run log

$\begin{array}{ll}\text { CLP } & \text { - contract laboratory program } \\ \text { GC } & \text { - gas chromatography } \\ \text { GFAA } & \text { - graphite furnace atomic absorption } \\ \text { ICP } & \text { - inductively coupled plasma } \\ \text { LCS } & \text { - laboratory control sample } \\ \text { MS } & \text { - mass spectrometry } \\ \text { RPD } & \text { - relative percent difference } \\ \text { RSD } & \text { - relative standard deviation } \\ \text { TIC } & \text { - tentatively identified compound }\end{array}$


Data validation criteria are as follows:

\section{Organics \\ Holding Times \\ Blanks \\ Surrogate Recovery \\ Internal Standards \\ Calibration \\ Sample Reanalysis \\ Secondary Dilutions \\ Case Narrative}

\author{
Inorganics \\ Holding Times \\ Blanks \\ Laboratory Control Sample \\ Furnace Atomic Absorption QC
}

Calibration

Case Narrative

\author{
Radiochemistry \\ Holding Times \\ Blanks \\ Laboratory Control Sample \\ Sample Specific Chemical or \\ Tracer Recovery \\ Calibration
}

Case Narrative

\subsubsection{Data validation criteria}

Holding Times. Evaluation of holding times ascertains the validity of results based on the length of time from sample collection to sample preparation or sample analysis. Verification of sample preservation must be confirmed and accounted for in the evaluation of sample holding times. The evaluation of holding times is essential to establishing sample integrity and representativeness. Concerns regarding physical, chemical, or biochemical alteration of analyte concentrations can be eliminated or qualified through this evaluation.

Blanks. The assessment of blank analyses is performed to determine the existence and magnitude of contamination problems. The criteria for evaluation of blanks applies to any blank associated with the samples, including field, trip, equipment, and method blanks. Contamination during sampling or analysis, if not discovered, results in false positive data.

Surrogate Recovery. System monitoring compounds are added to every sample, blank, matrix spike (MS), matrix spike duplicate (MSD), and standard. They are used to evaluate extraction, cleanup, and analytical efficiency by measuring recovery on a sample-specific basis. Poor system performance as indicated by low surrogate recoveries is one of the most common reasons for data qualification. Evaluation of surrogate recovery is critical to the provision of reliable sample-specific analytical results.

Calibration. The purpose of initial and continuing calibration verification analyses is to verify the linear dynamic range and stability of instrument response. Relative instrument response is used to quantify the analyte results. If the relative response factor is outside acceptable limits, the data quantification is uncertain and requires appropriate qualification.

Internal Standards. Internal standards are utilized to evaluate and compensate for sample-specific influences on the analyte quantification. They are evaluated to determine whether data require qualification due to excessive variation in acceptable internal standard quantitative or qualitative performance measures. For example, a decrease or increase in internal standard area counts for organics may reflect a change in sensitivity that can be attributed to the sample matrix. Because quantitative determination of analytes is based on the use of internal standards, evaluation is critical to the provision of reliable analytical results.

Sample Reanalysis. When instrument performance-monitoring standards indicate an out-of-control analysis, the laboratory is required to re-analyze the sample. If the re-analysis does not solve the 
problem (i.e., surrogate compound recoveries are outside the limits for both analyses), the laboratory is required to submit data from both analyses. An independent review is required to determine which is the appropriate sample result.

Secondary Dilutions. When the concentration of any analyte in any sample exceeds the initial calibration range, a new aliquot of that sample must be diluted and reanalyzed. The laboratory is required to report data from both analyses. When this occurs, an independent review of the data is required to determine the appropriate results to be used for that sample. An evaluation of each analyte exceeding the calibration range must be made, including a review of the dilution analysis performed. Results chosen in this situation may be a combination of both the original results (i.e., analytes within initial calibration range) and the secondary dilution results.

Laboratory Control Samples (LCS). The LCS serves as a monitor of the overall performance of the analytical process, including sample preparation, for a given set of samples. Evaluation of this standard provides confidence in or allows qualification of results based on a measurement of process control during each sample analysis.

Furnace Atomic Absorption QC. Duplicate injections and furnace post-digestion spikes are evaluated to establish precision and accuracy of individual analytical determinations. Because of the nature of the furnace atomic absorption technique and because of the detailed decision tree and analysis scheme required for quantitation of the elements, evaluation of the $\mathrm{QC}$ is critical to assuring reliable analytical results.

Sample Specific Chemical or Tracer Recovery. Laboratory performance on individual samples subject to chemical process and separation is established by means of spiking with tracer quantities of other radioisotopes of the same element or carrier quantities of an inactive isotope of the same or a chemically similar element. This process is analogous to surrogate or internal standard recovery, dependent on the analyte and method being evaluated, and is a common reason for data qualification.

\subsubsection{Project Data Quality Assessment}

Data quality indicator parameters, precision, accuracy, representativeness, completeness, and comparability (PARCC) will be used to evaluate data quality and quantity. Both qualitative and quantitative criteria are used as indicators of the quality of the data. In determining data usability, especially in the decision-making process, the integrity and authenticity of the data must be evaluated and the analytical uncertainty must be determined. Parameters used to assess data quality for this investigation are precision, accuracy, representativeness, comparability, completeness, and sensitivity. These parameters will be evaluated as directed by project management.

\subsection{QC CHECKS}

\subsubsection{Field QC Checks}

QC samples will be collected at a frequency as identified in this QAPjP to assess the quality of sampling. Field QC samples include blanks, rinsates, and duplicates. 


\subsubsection{Equipment rinsates}

An equipment rinsate is a sample of the last rinse using ASTM Type I water that has been pumped into or poured through the sampling equipment. Equipment rinsates will be collected at a minimum rate of $5 \%$ of the samples collected. The purpose of these rinsates is to check for residual contamination as a measure of the effectiveness of decontamination. The equipment associated with the unique sample identifier should be identified in the field logbook. Equipment rinsates are analyzed for the same analytes as samples collected. Equipment rinsates are not required for dedicated sampling equipment.

\subsubsection{Field duplicates}

Field duplicates will be collected concurrently with primary samples. Duplicates will be completed in the field when using field analytical techniques or sent to the laboratory responsible for analyses. Field duplicates will be collected at a frequency of $10 \%$ of the samples collected (i.e., 1 to 10 samples collected equals 1 field duplicate; 11 to 20 samples collected equals 2 field duplicates).

\subsubsection{Nitrate split confirmation samples}

Ten percent of the rapid screening samples for in-field nitrate analysis will be divided into two subsamples, with one being sent to the fixed laboratory for confirmation analysis.

\subsubsection{Analytical QC Procedures}

A number of analytical QC samples will be analyzed to check and monitor laboratory performance, precision, and accuracy. Analytical QC is necessary to assess potential impacts of interferences and contaminants during the analytical process.

\subsubsection{Analytical duplicates}

Analytical duplicates are separate aliquots of a single sample that are prepared and analyzed concurrently. This duplicate sample should not be a method blank, trip blank, or field blank. The primary purpose of the analytical duplicate is to check the precision of the analytical analyst, the sample preparation methodology, and the analytical methodology. If there are significant differences between the duplicates, the affected analytical results will be re-examined. One in 20 samples will be an analytical duplicate, with fractions rounded to the next whole number. In-field nitrate analysis will include analytical duplicates.

\subsubsection{Analytical method blanks}

A method blank is a sample made up of a pure, noncontaminated substance of the matrix of interest (usually distilled/deionized water or silica sand) that is then subjected to all of the sample preparation (digestion, distillation, extraction) and analytical methodology applied to the samples. The purpose of the method blank is to check for contamination that might be introduced during sample preparation and analysis that would adversely affect analytical results. A method blank must be analyzed with each analytical sample batch. In-field nitrate analysis will include method blanks. 


\subsubsection{Laboratory control sample}

The LCS contains known concentrations of analytes representative of the contaminants to be determined, or are added to laboratory ASTM Type II water and carried through the entire preparation and analysis process. Commercially available LCSs or those from EPA may be used. LCS standards that are prepared in-house must be made from a source independent of that of the calibration standards. For methods using surrogates, the method blank may be used as the LCS. Each LCS analyte must be plotted on a control chart. The primary purpose of the LCS is to establish and monitor the laboratory's analytical process control. An LCS must be analyzed with each analytical sample batch.

\subsubsection{MSs and MSDs}

An MS is an aliquot of a sample spiked with known quantities of analytes and subjected to the entire analytical procedure. It is used to indicate the appropriateness of the method for the matrix by measuring recovery or accuracy. Accuracy is the nearness of a result or the mean of a set of results to the true or accepted value. An MSD is a second aliquot of the same sample as the MS with known quantities of compounds added. The purpose of the MSD, when compared to the MS, is to determine method precision. Precision is the measure of the reproducibility of a set of replicate results among themselves or the agreement among repeat observations made under the same conditions. MSs and MSDs are performed per 20 samples of similar matrix.

\subsubsection{Method-specific QC}

The laboratory must follow specific quality processes as defined by the method. These will include measures such as calibration verification samples, instrument blank analysis, surrogate determinations, internal standards, tracer analysis, etc.

\subsection{AUDITS AND SURVEILLANCE}

\subsubsection{Audits}

Audits are performed to review and evaluate the adequacy of field and laboratory performance and to ascertain whether the QAPjP is being completely and uniformly implemented. There are no scheduled audits for the project at this time. Audits may be implemented at the direction of Energy Systems or DOE. These audits shall be conducted in accordance with written procedures and checklists and shall be performed by personnel who do not have direct responsibility for performing the activities being audited. Energy Systems audits will be conducted in accordance with ESS-QA-18.0 and ESS-QA-18.1. Any SAIC audit will be conducted in accordance with SAIC Quality Assurance Administrative Procedure (QAAP) 18.1.

The project QA/QC Officer is responsible for audits and may perform them as directed by project management.

Laboratory audits are performed annually by the OR SMO to review and evaluate the adequacy of laboratory practices, procedures, and systems. These planned and scheduled audits are performed to verify compliance with all aspects of the Energy Systems QA program and to determine the program's

effectiveness. These audits shall be conducted in accordance with written procedures and checklists and 
shall be performed by trained technical personnel. Energy Systems audits will be conducted in accordance with ESS-QA-18.0 and ESS-QA-18.1 and in conjunction with DOE OR Operations. Once the OR SMO has designated a laboratory(s) to support this work, documentation of these audits including resolution and close-out of all corrective actions, shall be provided to the SAIC Project Management for incorporation in the project files.

In the event SAIC personnel participate in these systematic audits during the project time frame or SAIC is tasked through the project to implement a laboratory performance audit, the SAIC audit will be conducted in accordance with SAIC QAAP 18.1 and focus on project specific performance issues.

\subsubsection{Surveillance}

Surveillance activities include monitoring and observing documents and work activities to provide an effective real-time means of evaluating the adequacy and effectiveness of methods for achieving quality and for assessing the quality of final results. Energy Systems surveillance will follow ER/C-P1600 Performance of Surveillance Activities, as applicable. SAIC surveillance will follow SAIC QAAP 18.3.

One field surveillance will be conducted during the BCV Treatability Study as early in the sampling event as practical for the project. The surveillance will cover each type of sampling in the SAP: groundwater, surface water, and media testing.

Laboratory activities are not scheduled for project surveillance at this time. In the event issues arise during the course of the investigation that indicate a surveillance is warranted, such tasks will be conducted in accordance with Energy Systems ER/C-P1600 Performance of Surveillance Activities and SAIC procedure QAAP 18.3.

\subsection{PREVENTIVE MAINTENANCE PROCEDURES/SCHEDULES}

Any equipment (an inclusive term for tools, gauges, instruments, and other items that have specific preventive maintenance) will be serviced and documented as specified by the manufacturer's recommended schedule. All service will be performed by qualified and trained individuals. The operators are responsible for seeing that the equipment is scheduled for service, serviced, and properly maintained. Properly maintained equipment helps reduce unnecessary "downtime." A complete list of equipment will be developed by the operator and the parts or replacement equipment will be immediately available (either from the supplier/manufacturer or on site). Having replacement equipment or critical spare parts available minimizes "downtime."

The implementation of a preventive maintenance program depends on the specific instruments and equipment used for the field. Both field and laboratory efforts will ensure a preventive maintenance program that includes the following:

- A listing of the instruments and equipment in the program, including backup alternatives.

- The frequency of maintenance considering manufacturer's recommendations and/or previous experience with equipment. 
- External service contracts.

- Checklists of items to be serviced and directions for maintenance or manufacturer's instrument manuals.

- Records of periodic and routine maintenance performed.

\subsection{SPECIFIC ROUTINE PROCEDURES}

The analytical data assessment objectives for laboratory analysis will produce data of known and sufficient quality to support the investigation and its resulting decisions. Appropriate procedures and QC checks will be employed to assess the level of acceptance of these parameters. All QC data will be reported for the project along with the sample results. When the analytical sample set is completed, QC data will be reviewed and evaluated to validate the information. Acceptance criteria and evaluation of laboratory analytical results for the PARCC parameters will be determined according to the following outline.

Procedures to attain sensitivity objectives include (1) measurement of analyte levels in field and laboratory blanks; (2) uniform training and certification for staff; (3) standard provisions for inspection, maintenance, and repair; (4) provision of standard operating procedures to technical staff; (5) reference to standard operating procedures in the Field and Laboratory QAPjPs; and (6) field/laboratory QA inspections to determine compliance with the items specified in the support plans.

\subsubsection{Precision}

Precision is defined as the reproducibility or degree of agreement among duplicate measurements under a given set of conditions. The closer the measurements approach each other, the more precise the measurement. The level of precision is determined by calculating the relative percent difference (RPD) between the two measurements, using the following formula:

$$
R P D=\frac{[S-D]}{(S+D) / 2} \times 100 \%
$$

where:

$\mathrm{S}=$ analyte concentration of the original sample,

$\mathrm{D}=$ analyte concentration of the duplicate sample.

Precision is determined relative to field duplicate pairs, laboratory duplicate pairs, and laboratory MS/MSD analyses. In the event analytical precision goals are exceeded, a determination will be made through the data validation process relative to the usability of that information. 


\subsubsection{Accuracy}

Accuracy is defined as the degree of difference between measured values and the true values. Sampling accuracy will be maximized by adhering to the QA program presented in the QAPjP. Accuracy will be assessed by splitting a sample into two portions, spiking (i.e., adding known quantity of the constituents of interest to one of the portions), and then analyzing both portions for these parameters. The difference in the concentration levels of the constituents of interest should be equal to the quantity of the spike added to one of the two portions. The following equation will be used to calculate percent recovery $(\% R)$ :

$$
\% R=\frac{A r-A o}{A f} \times 100 \%
$$

where:

$\mathrm{A}_{\mathrm{r}} \quad=$ total compound or element concentration detected in the spiked sample,

$\mathrm{A}=$ concentration of the compound or element detected in the unspiked sample,

$\mathrm{A}_{\mathrm{f}}^{\mathrm{o}}=$ concentration of the compound or element added to the sample.

For situations in which a standard reference material (SRM) is used rather than or in addition to MSs, the following formula is used:

$$
\% R=\frac{C_{m}}{C_{s r m}} x 100 \%
$$

where:

$$
\begin{array}{ll}
\mathrm{C}_{\mathrm{m}} & =\text { measured concentration of SRM, } \\
\mathrm{C}_{\mathrm{sm}} & =\text { actual concentration of SRM. }
\end{array}
$$

\subsubsection{Representativeness}

Representativeness expresses the relative degree to which the data depict the characteristics of a population, parameter, sampling point, process condition, or environmental condition. The objective of this study is to accurately represent the chemical concentrations of target analytes.

Representative samples for this investigation will be acquired through implementation of approved sampling and analytical procedures that will generate data representative of the sampling point location. Sampling procedures are designed to minimally impact the sample obtained, so that conditions representative of the sampling location will be maintained. Analytical methods will be selected that most accurately represent the true concentration of the parameter of interest. The accumulation of QC procedures and information (i.e., RPD values, blank QC concentrations, MS percent recoveries, etc.) employed for a given analysis combine to exhibit the representativeness of the data generated. 
The goal for representative sample data will, therefore, be met through the proper documentation of field and analytical protocols. If these procedures and methods cannot be implemented, the appropriate corrective action documentation will encompass the impact on the representativeness of the information. Review of the data, documentation, and field information will also be implemented to identify sample population, parameter, or process characteristics relative to representativeness.

\subsubsection{Completeness}

Completeness is defined as the percentage of valid data obtained from a measurement system. For data to be considered valid, it must have met all acceptance criteria, including accuracy and precision, as well as any other criteria specified by the analytical methods used. Percent completeness (\%C) is calculated as follows:

$$
\% C=\frac{V}{n} x 100 \%
$$

where:

$\mathrm{V}=$ the actual number of valid measurements obtained,

$\mathrm{n}=$ the number of sample points planned.

To meet the objectives of this project, all data will be validated against the data validation guidance (Sect. 4.7.3) to determine its usability. For determination of completeness in this project, all data not flagged as rejected by the validation process will be considered valid. When review of the data and documentation determines the data to be incomplete, the impact relative to the project objectives will be assessed and documented.

\subsubsection{Comparability}

Comparability expresses the confidence with which one data set can be compared with another. Comparability of the data generated in this investigation will be obtained through the implementation of the identified protocols for sampling and analysis of samples. Use of traceable reference materials as laboratory standards, expression of results in standard concentration units, and successful participation by the laboratories in external performance evaluation programs will enable the data produced through this investigation to be compared with future groundwater sampling data sets.

\subsection{CORRECTIVE ACTION}

Energy Systems corrective actions to audit/surveillance findings and nonconformance will be managed in accordance with ESS-QA-16.0, 16.1, 16.2, 16.3, 16.4, and ESS-QA-15.0 and 15.1. SAIC corrective actions to audit/surveillance findings and nonconformances will be managed in accordance with SAIC QAAP 15.1 and 16.1. The Energy Systems Project Manager will be notified when a nonconformance is documented and furnished a copy as soon as possible. Copies of nonconformances and their dispositions will be forwarded to the Energy Systems Project Manager for placement in the EMEF Records Center. NCRs issued as a result of an audit or surveillance will identify the root cause of the problem. 


\subsection{QA REPORTS TO MANAGEMENT}

All QA records concerning the project (e.g., internal and external correspondence, sampling and analysis plan, QAPjP, field logbooks and forms, chain-of-custody forms, data packages, audit reports, surveillance reports, NCRs, corrective action reports, etc.) will be submitted to the SAIC Central Records Facility for dual storage and retrieval. Records concerning the project will be forwarded to the Energy Systems Project Manager upon request for placement in the EMEF Records Center during the project. A complete copy of the project file will be submitted to the Energy Systems Project Manager at the end of the period of performance. 


\section{DATA MANAGEMENT PLAN}

\subsection{OBJECTIVES}

This DMP describes the standards and practices that will be implemented for the Bear Creek Valley Phase II Treatability Study. This project is being conducted by a multidisciplinary team of researchers from several different organizations and will consist of a number of concurrent investigative activities. In order to effectively implement this team approach, data documentation and accessibility will be critical. This DMP will provide the necessary level of control to ensure that data of appropriate confidence and quality are obtained and made available in useful formats to the entire project team.

In addition, a data management implementation plan will be developed in accordance with ES/ER/TM88/RI and this DMP to further document data management activities. Existing record management plans, information management procedures, and data base management systems will be used to track, document, and manage all field and analytical data. Procedures required for data management are listed in Table 15.

\subsection{DATA NEEDS, SOURCES AND TYPES}

The investigative activities proposed for this phase of work will result in the collection of a variety of data types for defining the efficiency and feasibility of potential groundwater and surface water treatment technologies. Activities expected to generate data include:

- field measurement of physical and chemical properties of environmental media,

- field measurement of physical and chemical properties of treatment media,

- documentation of sampling and monitoring activities,

- laboratory analyses of environmental and treatment media, and

- measurement of meteorological and environmental conditions.

Data sources will include laboratory electronic deliverables and field notebooks and logbooks. In addition, historical analytical data from the Y-12 Groundwater Protection Program data base are needed to establish baseline conditions.

\subsection{ROLES AND RESPONSIBILITIES}

\subsubsection{Primary Roles}

For this project, the two primary roles relative to management of project data are the data generator and the data coordinator. Principle investigators who are responsible for the collection of project-related data are the generators for those data. Data generators have the ultimate responsibility for the quality and validity of the data they produce. The data coordinator is responsible for receiving, documenting, and making available all data submitted by the data generators and/or by off-site analytical laboratories. This role includes documenting data base contents, verifying the completeness of data packages and assuring the accuracy of file transfers between the data generators and the project data base. 
Table 15. Data management procedures

\begin{tabular}{lllc}
\hline \multicolumn{1}{c}{ Procedure } & \multicolumn{1}{c}{ Subject activity } & Issue date & Revision \\
\hline ERWM/ER-P2205 & $\begin{array}{l}\text { Development, Completion, and Control of Data Forms and } \\
\text { Loggbooks }\end{array}$ & $03 / 23 / 95$ & 0 \\
TP-DM-300-6 & Data Package Receipt and Verification (modified) & $04 / 16 / 93$ & 2 \\
TP-DM-300-7 & Data Validation & $09 / 20 / 96$ & 3 \\
TP-DM-300-8 & Field Data Validation & $09 / 20 / 96$ & 2 \\
TP-DM-300-9 & Analytical Data Nonconformance (modified) & $04 / 16 / 93$ & 0 \\
ERWM/ER-P2207 & Backup and Restoration Processes for Environmental Data & $08 / 02 / 95$ & 0 \\
& Management Systems Within the Environmental Restoration & & \\
EM\&EF/ER-P2214 & Environmental Data Entry, Transfer, and Transformation & $09 / 06 / 96$ & 0 \\
& Verification & $04 / 96$ & 3 \\
ERWM/ER-P2701 & Transmitting Data to OREIS & $09 / 20 / 96$ & 0 \\
EM\&EF/ER-P2215 & Archival of Environmental Data Within the EMEF Program & & \\
\hline
\end{tabular}

Other roles and responsibilities associated with data management activities include:

Data Manager. The Data Manager oversees all data management activities;. interfaces with other organizations as necessary to facilitate communication and timely and efficient data transfer; and identifies and acquires all relevant data, including historical data as appropriate.

Field Operations Manager. The FOM helps prepare the SAP and implements it in the field and assigns staff members to sampling; prepares for and coordinates sampling activities; oversees field data collection, recording, and documentation activities including any electronic data capture implemented in the field.

Sample Manager. The Sample Manager supervises packing and shipping of samples to the laboratory.

Records Manager. The Records Manager controls the recorded information about project activities that is generated and/or received by project organizations and provides all necessary Administrative Record information to the client at project closeout.

Laboratory Coordinator. The Laboratory Coordinator interfaces with off-site laboratories and project personnel to resolve issues related to laboratory services. 
4.3.2 Data Management Contacts

$\begin{array}{lllll}\text { Role } & \text { Organization } & & \text { Name } & \text { Phone } \\ \text { Project Manager } & \text { Energy Systems } & & \text { John Vanderlan } & 546-2745 \\ & \text { SAIC } & & \text { Maureen Leavitt } & 481-4614 \\ \text { Data Manager } & \text { Energy Systems } & & \text { Virginia Forsberg } & 574-7000 \\ & \text { SAIC } & & \text { Jennifer Chason } & 481-8796 \\ \text { Data Coordinator } & \text { SAIC } & & \text { Leslie Barbour } & 481-8768 \\ \text { Field Operations Manager } & \text { SAIC } & & \text { Dan Thompson } & 481-4750 \\ \text { Sample Manager } & \text { SAIC } & & \text { Scott Lane } & 481-8740 \\ \text { Records Manager } & \text { SAIC } & \text { Connie Chavannes } & 481-4777 \\ \text { Laboratory Coordinator } & \text { Energy Systems } & \text { Jim Davis } & 481-4751\end{array}$

\subsection{DATA MANAGEMENT ACTIVITIES}

\subsubsection{Data Collection Documentation}

\subsubsection{Key identifiers}

Each investigative activity that generates samples for laboratory analysis will use a unique code for identification purposes (e.g., CP for column panel studies). For each sampling event, sample identification numbers will be assigned based on the activity code, sampling station, media, sample type (regular or field QC), and sequence of the sample. Based on this scheme, all field samples collected under this project will have a unique sample number. Field sample numbers will be documented in the field $\log$ books as they are collected and placed on sample labels, chain-of-custody forms, and any other documentation regarding the sample.

\subsubsection{Field documentation}

Measurements taken in the field and any descriptive information required to adequately identify them will be recorded on standardized field forms by the cognizant field team member. Checklists will also be developed by the data manager and FOM to document routine monitoring activities. Procedures for recording logbook information (see Sect. 3.3) should ensure legible and clear entries. Logbooks and any other field documentation will be available to project team members only and will be stored in a locked cabinet when not in use. Copies will be made regularly and stored in a separate location to protect from fire or other loss.

Originals of logbooks will be provided to the records coordinator following the field event and will be indexed and included in the project files. Any data entry required from field forms will be performed under the direction of the data coordinator and will be verified by $100 \%$ review against the original document.

Sample collection and transfer to the analytical laboratory will be documented using standard chainof-custody forms and proper chain-of-custody protocol (Sec. 3.4). Laboratories receiving Federal Express shipments will return a completed and signed copy of the chain-of-custody form to the laboratory coordinator within $24 \mathrm{~h}$ of receipt of the sample. Copies of chain-of-custody forms for 
samples collected by or relinquished to on-site research laboratories will be provided to the data coordinator by the responsible field team member.

\subsubsection{Laboratory data deliverables}

All data generated by laboratory analysis will be reported in both hardcopy and electronic forms. Specific file formats will be described in the laboratory statements of work and in the DIP. In addition, all electronic data deliverables will include the field sample number in addition to the laboratory sample identification number.

All analyses from off-site laboratories will be reported to the laboratory coordinator (at the SMO), and one copy of each will be forwarded to the data coordinator for validation and data base update purposes. Laboratory analyses generated by on-site research laboratories may be reported to the data

generator. In this case, a copy will be forwarded to the data coordinator after review by the data generator.

\subsubsection{Data Capture and Consolidation}

An electronic version of all measurement and descriptive data generated by the field team will be consolidated in one location and made available to all project team members. This location will be a designated directory on the SAIC Internet server and will be password protected. Sufficient descriptive information will be maintained along with the data files to allow users to locate and download specific types of information. As new data are posted, the data coordinator will notify the project team of the additions via electronic mail.

The files will be organized as logically as possible, e.g., by data generator. Rather than forcing all data into a single structure, data files of different types will be maintained separately in either text, spreadsheet, or database format as determined by the data generator and the data manager. An appropriate file format will be determined for each type of data obtained and will include at a minimum the following data elements:

- activity,

- station or site,

- date collected,

- measured or observed,

- measurements or descriptive information, and

- responsible contact.

Data requiring manual entry from field notes will be the responsibility of the data generator. Processing and qualification of any data logged electronically in the field or obtained from research laboratories will likewise be the responsibility of the data generator. (Note that the data generators may delegate this to the data coordinator within the constraints of the contract agreement.) Any data file prepared by a data generator can be posted directly to the file server, or can be transferred to the data coordinator using clearly labeled diskettes. In either case, adequate descriptive information including dates, type and source of the data, methods used, result qualifiers, and specific location information will be provided by the data generator. A simple form for documenting data transfer will be developed and made available in both hard and soft copy. 
For samples shipped for off-site laboratory analyses, all pertinent sampling information such as date and time collected and requested analyses will be captured electronically (entered from logbooks) by the data coordinator. The data coordinator will also receive electronic data deliverables of the laboratory results, combine them with the sample collection data, provide the results to the data generator for review, and update the data base or post the resulting file on the server.

\subsubsection{Data Verification and Validation}

Electronic deliverables received by the data coordinator will be checked against chain-of-custody forms (and logbooks if appropriate) for completeness and accuracy. Questions about sample identification or collection will be forwarded to the data generator for resolution. Data entry of all sampling information or measurement data completed by the data coordinator will be verified before being posted for use by the project team.

For the baseline samples to be analyzed by commercial laboratories, SAIC will perform a basic validation (see Sect 3.7.3) on $100 \%$ of the data. Validation and verification of all other sample results or field data will be the responsibility of the data generators.

\subsubsection{Version Control}

Version numbers will be maintained as part of each data file name. After a data set is posted to the project data directory, all subsequent changes must be approved by the data generator and the date and nature of the change documented. The superseded file will be moved to an archive area rather than deleted, replaced with a modified file, and the version number incremented.

\subsection{TRANSMITTALS AND ARCHIVAL OF DATA}

\subsubsection{OREIS Transmittals}

After all data collection activities are complete, an OREIS deliverable of project-generated data will be prepared by the data manager. These files will be submitted to OREIS following ERWM/ER-P207.

\subsubsection{Data Archival}

Project data will be backed-up nightly as part of routine network management procedures. Upon completion of the project, all project data will be archived to tape and submitted to the project file. Sufficient documentation will accompany the archived data to fully describe the source, contents, and structure of the data to ensure future data usability. Computer programs used to manipulate or report the archived data will be included in the data archive information package to further enhance the future usability of the data.

Hard copies of all original field and analytical results, data verification programs, data packages, and associated QA/QC forms will be clearly labeled, filed, and stored as part of the project files. The records coordinator will ensure that all required Administrative Record File documents are acquired and indexed and will submit the records to Energy Systems at project closeout. 


\section{DISTRIBUTION}

1. L. V. Asplund

2. J. A. Davis

3. V. M. Forsberg

4. C. S. Haase

5. J. C. Henderson

6. R. L. Marcum

7. L. E. May

8. H. C. Newson

9. P. T. Owen

10. L. B. Raulston

11. L. G. Schaffer

12-14. J. H. Vanderlan

15. D. B. Watson

16. S. A. White

17. M. C. Wiest

18. File-EMEF DMC-RC

19. R. Adkisson, Entech, 560 Oak Ridge Turnpike, Suite 2, Oak Ridge, Tennessee 37830

20. M. Leavitt, Science Applications International Corporation, 800 Oak Ridge Turnpike, P.O. Box 2502, Oak Ridge, Tennessee 37831

21. D. Moss, Science Applications International Corporation, 800 Oak Ridge Turnpike, P.O. Box 2502, Oak Ridge, Tennessee 37831

22. B. Sams, Jacobs Engineering Group, Inc., 125 Broadway Avenue, Oak Ridge, Tennessee 37830 